Luiz Ricardo de Miranda

\title{
O Grupo Banco Mundial e a regulação internacional do financiamento de projetos (Project Finance)
}

Tese apresentada na Faculdade de Direito da Universidade de São Paulo, como requisito parcial para obtenção de título de Doutor em Direito.

Área de Concentração: Direito Internacional e Comparado

Orientador: Professor Titular Dr. Paulo Borba Casella

Faculdade de Direito da Universidade de São Paulo São Paulo 


\section{Resumo}

Intensificadas pelo processo de globalização, as transformações no direito internacional ganharam novo impulso ao longo do último século, sobretudo a partir de sua segunda metade. A criação e, em seguida, extensão das atividades das organizações internacionais fazem parte desse processo.

No caso do Grupo Banco Mundial, nascido como uma única organização, esse processo tomou proporções extraordinárias, seja pelo seu desenvolvimento funcional, seja estrutural. Obviamente, mudanças de tais proporções causam impactos inevitáveis sobre o direito.

Nesse trabalho, essas transformações são visualizadas através de um instrumento bastante peculiar: o financiamento de projetos (project finance). Importado da economia, essa mecânica de financiamento tem feições jurídicas ainda um tanto opacas. Quanto ao Banco Mundial, ele intervém nesse processo de inúmeras maneiras: através da concessão de empréstimos, garantias, até mesmo resolvendo conflitos. O desenvolvimento dessa gama de atividades inevitavelmente levou a adquirir competências de regulador que originalmente não possuía.

Palavras chave: Banco Mundial; Financiamento de projetos, Project finance; Investimentos estrangeiros 


\begin{abstract}
Globalization has intensified the transformations within International Law during the last century, especially its second half. The international organizations' creation and, afterwards activities development are important parts of this process.

Concerning the World Bank Group, which had been born as a single institution, this process took extraordinary proportions in both senses through its structural and functional development. Obviously, such changes cause inevitable impacts on law.

Within this work, we approach these changes through a very peculiar instrument: project finance. Imported from economics, this mechanism has very uncertain legal features yet. Concerning the World Bank, it intervenes within this process in different ways: according loans, guarantees or even resolving conflicts. The development of this broad agenda inevitably gave it some regulatory powers it hadn't originally had.
\end{abstract}

Key words: World Bank: Project finance; Foreign Investments 


\section{Resumen}

Con la intensificación de la globalización, las transformaciones en el derecho internacional han adquirido un nuevo impulso en el último siglo, sobre todo a partir de su segunda mitad. La creación y, en la secuencia, la extensión de las actividades de las organizaciones internacionales son parte de ese proceso.

En el caso del Grupo Banco Mundial, que nació como una sola organización, ese proceso tomó proporciones extraordinarias, sea por su desarrollo funcional o estructural. Obviamente, las transformaciones de tales proporciones causan impactos inevitables del derecho.

En este trabajo, esas transformaciones son vistas a través de un instrumento muy peculiar: la financiación de proyectos (project finance). Importado de la economía, este mecanismo de financiamiento tiene todavía características jurídicas algo opaco. Cuanto al Banco Mundial, él interviene en ese proceso de muchas maneras: por la concesión de préstamos, garantías, y aún por la resolución de conflictos. El desarrollo de esa gama de actividades inevitablemente condujo el Banco a adquirir las habilidades que el regulador originalmente carecía.

Palabras clave: Banco Mundial, Project Finance, Inversiones Extranjeras 


\section{Introdução}

\section{Parte I}

\section{A regulação internacional: aspectos gerais}

\section{Capítulo 1}

\section{Do direito à regulação internacional}

1.1 Direito internacional: racionalidade sistêmica

Cooperação internacional

(p. 21)

1.2 Organizações internacionais: a institucionalização da cooperação internacional

Da Liga das Nações à Organização das Nações Unidas (p. 46)

1.3 Direito internacional: uma nova configuração

A natureza jurídica das organizações internacionais

(p. 62)

\section{Capítulo 2}

\section{A internacionalização da noção de regulação}

2.1 Regulação da atividade econômica

Estado regulador: um modelo universal de Estado?

2.2 A regulação no âmbito internacional

A Organização Internacional como agente regulador

2.3 A racionalidade da regulação

O caso do Banco Mundial

(p. 116)

\section{Capítulo 3}

\section{A regulação internacional do Project Finance}

3.1 Project Finance: noções gerais

Agentes e estrutura

3.2 Os riscos

Os riscos não comerciais

(p. 155)

3.3 Agentes reguladores e instrumentos regulatórios riscos (p. 162) 
Contratos com o Estado (Contrat d'Etat)

(p. 169)

3.4 A regulação internacional dos investimentos estrangeiros (p. 182)

O direito internacional dos investimentos como exemplo de transformação do direito internacional

(p. 188)

\section{Parte II}

Project Finance: o Grupo Banco Mundial como agente regulador

\section{Capítulo 4}

Banco Mundial: “da reconstrução ao desenvolvimento às finanças"

4.1 Mandato

4.2 A evolução das ações do Banco no tempo estrutural

Ajustes estruturais

4.3 O poder de interpretar os próprios estatutos Atos ultra vires

4.4 Aspectos jurídicos relativos à evolução do Banco (p. 244) Considerações estruturais relativas à às transformações do BIRD

\section{Capítulo 5}

\section{Mecânica institucional}

5.1 A diversificação estrutural

(p. 269)

IDA

(p. 272)

IFC

(p. 280)

ICSID

(p. 284)

MIGA

(p. 288)

5.2 O sistema Banco Mundial e o setor privado

(p. 295) 
O Banco Mundial e o project finance

(p. 301)

5.3 A condicionalidade

(p. 306)

O conteúdo material da condicionalidade

(p. 315)

As fontes e os limites da condicionalidade

(p. 320)

\section{Capítulo 6}

O financiamento de projetos no âmbito do Grupo Banco Mundial (instrumentos financeiros)

6.1 Operações Financeiras

Empréstimos soberanos

(p. 338)

Operações diretas envolvendo entidades privadas

Garantias

Painéis

(p. 355)

6.2 Solução de controvérsias

(p. 359)

ICSID

(p. 367)

6.3 O quadro regulatório geral

(p. 375)

Nível individual

(p. 377)

Nível global

(p. 385) 


\section{Introdução}

Il n'ont pas l'idée que c'est um autre monde où ils pénètrent et comme un milieu baigné d'une autre lumière, et que, s'ils y entraînent avec eux leur atmosphère, tout ce qu'ils essayeront de voir se trouvera déformé par une réfraction vicieuse. [...] [II] convient de nous dégager de nos habitudes intellectuelles, de renoncer à nos cadres tout faits, de nous laisser pénétrer lentement par les choses elles-mêmes et de démêler leur logique propre, au lieu de les plier à une méthode qui n'a pas été faite pour elles.

Émile Boutmy

No trecho em destaque, Boutmy ${ }^{1}$ adverte, com rara precisão e sutileza quase poética, acerca dos perigos a serem evitados pelo comparatista ao apreender o direito estrangeiro: automaticamente levados a traduzir o outro segundo nossa própria lógica, invariavelmente acabamos subtraindo-lhe a essência. Na época em que concebeu essa passagem (século XIX), provavelmente não the ocorreu que suas observações fossem igualmente válidas a outras áreas do conhecimento que tivessem no método comparativo sua principal ferramenta, tampouco que algum dia pudessem se aplicar ao direito internacional, disciplina não vinculada a um sistema jurídico determinado, mas particularmente sensível à ação do tempo.

Logo nas primeiras linhas de seu clássico Mudança na Estrutura do Direito Internacional, Friedmann oportunamente destaca que "a finalidade da lei é ordenação das relações sociais, todo o sistema jurídico deve refletir os princípios da ordem social que procura regulamentar"2. Muito mais que fixar um princípio elementar não raramente ignorado pelos juristas ao analisar os particularismos dos sistemas jurídicos, Friedmann conecta de maneira inexorável o direito, a sociedade e a história. A partir disso, somos levados a crer que o estudo do direito, particularmente do direito internacional, não pode prescindir do elemento histórico ${ }^{3}$. Parece-nos, portanto, inconcebível

1 BOUTMY, E. Études de droit constitutionnel. Paris: Plon, 1888. p.84-85. Disponível em: http://archive.org/stream/tudesdedroitcon01boutgoog\#page/n105/mode/2up. Último acesso em : 13 de janeiro de 2013

${ }^{2}$ FRIEDMANN, W. Mudança da estrutura do direito internacional. Rio de Janeiro: Freitas Bastos, 1964. p. 7.

3 "At present, in very many cases, if we want to know why a rule of law has taken its particular shape, and more or less if we want to know why it exists at all, we go to tradition. We follow it into the Year Books, and perhaps beyond them to the customs of the Salian Franks, and somewhere in the past, in the German forests, 
que um trabalho cujo cenário seja a evolução do direito internacional não tenha na análise histórica um de seus sustentáculos.

Daí a pertinência do alerta inicial feito por Boutmy. Ainda que se sinta tentado a automaticamente transpor conceitos que nos são familiares, ao analisar o direito a partir da perspectiva histórica é fundamental estar atento às naturais transformações que determinados institutos possam sofrer ao longo do tempo. Conquanto essencial à compreensão do fenômeno jurídico, há que se lembrar que a história permite uma visão instantânea de determinado instituto jurídico em determinada época, não se prestando, ao menos não de forma isolada, a descrever as suas feições atuais. Portanto, tentar retorcer os fatos a fim de encaixá-los em conceitos preconcebidos apenas confere uma ideia parcial da realidade: "tout ce qu'ils essayeront de voir se trouvera déformé par une réfraction vicieuse"4. É exatamente esse o perigo que se deve evitar ao se confrontar com uma análise histórica: deixar-se seduzir pelo que é familiar. Nesse mesmo sentido, Castells, ao reconhecer que períodos de transição tão intensa como o que vivemos podem revelar-se especialmente confusos, adverte que "as categorias intelectuais que usamos para compreender o que acontece à nossa volta foram cunhadas em circunstâncias diferentes e dificilmente podem dar conta do que é novo referindo-se ao passado".

Pois bem, no último século, o mundo, tal como o conhecíamos, passou por transformações extraordinárias. A despeito da ausência do necessário recuo histórico, fator que dificulta sobremaneira a apreensão da real extensão dessas mudanças, pode-se caracterizar este período pela fragmentação dos paradigmas locais e temporais ${ }^{6}$. Bauman, ao apontar a liquefação dos conceitos e ideias até então consolidados, sustenta que aquela sociedade, alvo das críticas da teoria crítica clássica, não mais existe: a modernidade pesada, sólida, condensada, sistêmica deu lugar a

in the needs of Norman kings, in the assumptions of a dominant class, in the absence of generalized ideas, we find out the practical motive for what now best is justified by the mere fact of its acceptance and that men are accustomed to it. The rational study of law is still to a large extent the study of history. History must be a part of the study, because without it we cannot know the precise scope of rules which it is our business to know." HOLMES, O. W. The Path of the Law. (in 10 Harvard Law Review 457, 1897). Disponível em: http://www.gutenberg.org/files/2373/2373-h/2373-h.htm. Último acesso em 13 de janeiro de 2013.

${ }^{4}$ BOUTMY, E., Études de droit constitutionnel. Cit., p.83.

${ }^{5}$ CASTELLS, M. A sociedade em rede. São Paulo: Paz e Terra, 2011. p. i (prefácio à edição 2010).

${ }^{6}$ CANOTILHO, J. J. G. Direito Constitucional. Coimbra: Almedina, 1993. p. 11-12. 
uma "nova modernidade", leve, fluida, capilar e em forma de rede ${ }^{7}$. Nessa nova configuração, não há mais porque se preocupar com a colonização do privado pelo público. Muito pelo contrário, houve mesmo uma nítida inversão da tarefa da teoria crítica:

A mesa foi virada, por assim dizer: a tarefa da teoria crítica foi invertida. Essa tarefa costumava ser a defesa da autonomia privada contra as tropas avançadas da "esfera pública", soçobrando sob o domínio opressivo do Estado onipotente e impessoal e de seus muitos tentáculos burocráticos ou réplicas em escala menor. Hoje a tarefa é defender o evanescente domínio público, ou, antes, reequipar e repovoar o espaço público que se esvazia rapidamente devido à deserção de ambos os lados: a retirada do "cidadão interessado" e a fuga do poder real para um território que, por tudo que as instituições democráticas existentes são capazes de realizar, só pode ser descrito como "espaço cósmico". Não é mais verdade que o "público" tente colonizar o "privado". O que se dá é o contrário: é o privado que coloniza o espaço público $[\ldots]^{8}$.

Mas a sublimação do individualismo não se concretizou sem os correlativos efeitos sobre o coletivo. Se como já em Tocqueville se suspeitava que o indivíduo fosse o pior inimigo do cidadão, a emergência do indivíduo causou um esvaziamento das questões públicas, convenientemente transformadas em fórum de afirmação dos interesses individuais ${ }^{9}$.

O individualismo não é, contudo, um elemento novo na sociedade ocidental. Suas raízes já eram claramente perceptíveis entre os valores que orientaram as revoluções do século XVIII. Contudo, por trás desse falso ar de normalidade, uma revolução silenciosa segue seu curso. A novidade dessa nova era parece residir no fim das grandes dicotomias que

\footnotetext{
7 "O tipo de modernidade que era alvo, mas também o quadro cognitivo, da teoria crítica clássica, numa análise retrospectiva, parece muito diferente daquele que enquadra a vida das gerações de hoje. Ela parece 'pesada' (contra a 'leve' modernidade contemporânea); ou melhor ainda, 'sólida' (e não 'fluida', 'líquida' ou 'liquefeita'), condensada (contra difusa ou 'capilar'); e, finalmente, 'sistêmica' (por oposição a 'em forma de rede').” BAUMAN, Z. Modernidade líquida. Rio de Janeiro: Jorge Zahar, 2001. p. 33.

${ }^{8}$ Idem, ibidem, p. 49.

9 "E assim há outro obstáculo: como de Tocqueville há muito suspeitava, libertar as pessoas pode torná-las indiferentes. $\mathrm{O}$ indivíduo é o pior inimigo do cidadão. $\mathrm{O}$ 'cidadão' é uma pessoa que tende a buscar seu próprio bem-estar através do bem-estar da cidade - enquanto o indivíduo tende a ser morno, cético ou prudente em relação à 'causa comum', ao 'bem comum', à 'boa sociedade' ou à 'sociedade justa'. Qual é o sentido de 'interesses comuns' senão permitir que cada indivíduo satisfaça seus próprios interesses? [...] Se o indivíduo é o pior inimigo do cidadão, e se a individualização anuncia problemas para a cidadania e para a política fundada na cidadania, é porque os cuidados e preocupações dos indivíduos enquanto indivíduos enchem o espaço público até o topo, afirmando-se como seus únicos ocupantes legítimos e expulsando tudo mais do discurso público.” Idem, ibidem, p. 45-46.
} 
caracterizavam a era moderna, contendo o individualismo dentro de uma esfera de ação delimitada. Libertado dessas amarras, sua penetração no interior da máquina estatal promoveu a apropriação do espaço público pelo indivíduo, expurgando do cenário político qualquer referência estranha à satisfação econômica ${ }^{10}$. Impulsionado pelo processo de globalização, o desenvolvimento do capitalismo - internacionalista por natureza atravessou as fronteiras nacionais, solapando lentamente outros sistemas sociais; condicionando, aos poucos, a política. Na passagem, a tradicional separação entre economia (privado) e política (público) foi paulatinamente superada à medida que se desfazia a associação entre interesses privados e interesses nacionais.

Não obstante sua grande popularidade, o termo globalização, usado para veicular uma grande quantidade de ideias, pode ser uma noção extremamente opaca. Trata-se, com efeito, de "uma palavra da moda que se transforma rapidamente em um lema, uma encantação mágica, umas senha capaz de abrir portas de todos os mistérios presentes e futuros" ${ }^{11}$. Muitas vezes, como no processo acima descrito, é assimilada a seus efeitos; outras, a propósitos políticos muito bem definidos. Identifica-se um desacordo muito grande quanto à definição de suas feições. Contudo, alguns pontos de consenso, ou quase, podem ser indicados.

Inúmero teóricos da globalização concordam precisamente na definição de seus traços essenciais. O elemento comum a qualquer análise acerca da globalização parece ser a informação: “a revolução tecnológica da informação e tudo o que ela conota em termos de comunicação instantânea e de compressão de tempo e espaço" ${ }^{12}$. Numa acepção mais ampla, o fenômeno da globalização caracteriza-se pela intensificação da interconectividade mundial em todos os aspectos da vida social ${ }^{13}$, podendo ser mais precisamente conceituada como

\footnotetext{
10 "Lembremos, no entanto, que tudo isso seria feito não para acabar de uma vez por todas com os sólidos e construir um admirável mundo novo livre deles para sempre, mas para limpar a área para novos $e$ aperfeiçoados sólidos." Idem, ibidem, p. 9.

${ }^{11}$ BAUMAN, Z. Globalização: as consequências humanas. Rio de Janeiro: Jorge Zahar, 1999. p. 7.

${ }^{12}$ KUMAR, K. Da sociedade pós-industrial à pós-moderna: novas teorias sobre o mundo contemporâneo. Rio de Janeiro: Jorge Zahar, 2006. p. 23.

13 "Globalization may be thought of initially as the widening, deepening and speeding up of the worldwide interconnectedness in all aspects of contemporary social life, from the cultural to the criminal, the financial to
} 
"um processo (ou conjunto de processos) que corporificam uma transformação da organização espacial das relações e transações - avaliadas em termos de extensão, intensidade, velocidade e impacto -, gerando fluxos e redes transnacionais e inter-regionais de atividade, interação e exercício do poder (Held et al., 1999:1)"14.

Numa abordagem pautada nos efeitos políticos, a globalização significa "os processos, em cujo andamento os Estados nacionais veem a sua soberania, sua identidade, suas redes de comunicação, suas chances de poder e suas orientações sofrerem a interferência cruzada de atores transnacionais" ${ }^{\prime 15}$. Em termos práticos, a compressão do espaço/tempo corrói as fronteiras nacionais, solapando a outrora sólida fidelidade nacional e substituindo-a por outros elementos, não necessariamente internacionais. Se, como aponta Bauman, o poder tornou-se extraterritorial, "Não importa mais onde está quem dá a ordem - a diferença entre próximo e distante, ou entre o espaço selvagem e o civilizado e ordenado, está a ponto de desaparecer" ${ }^{\prime 16}$. A partir dessas observações, algumas feições desse fenômeno não devem ser perdidas de vista.

Ao analisar especificamente o âmbito cultural, Lotman ${ }^{17}$ indica a não sincronicidade das transformações ao longo do tecido social. Em constatação similar, Kumar destaca a não linearidade da globalização ${ }^{18}$,

the spiritual." HELD, D. et al. Global transformations: politics, economics and culture. Stanford: Stanford University Press, 1999. p. 2.

${ }^{14}$ KUMAR, K. Da sociedade pós-industrial à pós-moderna: novas teorias sobre o mundo contemporâneo. Cit., p. 26.

${ }^{15}$ BECK, U. O que é Globalização? Equívocos do globalismo: respostas à globalização. São Paulo: Paz e Terra, 1999. p. 30.

${ }^{16}$ BAUMAN, Z. Modernidade líquida. Cit., p. 18.

17 "Esto no significa que cuando describamos la historia aislada de un arte dado nos toparemos aquí com uma interrupción: éste, al ser estudiado inmanentemente, parecerá ininterrumpito. Pero basta com que nos planteemos el objetivo de describir el conjunto de lãs artes em los marcos de tal o cual época, para que descubramos claramente la expansión de unas y 'como interrupciones' em la historia de otras. [...] Pero em el tejido real de la cultura la no sincronicidad no interviene como uma desviación casual, sino como uma ley regular. El arte transmisor que se halla em el apogeo de su actividad, al mismo manifiesta tiempo rasgos de espíritu innovador y de dinamismo. Los destinatários, por regra general, todavia están viviendo la etapa cultural precedente. Suele haber también otras relaciones, más complejas, pero la irregularidad tiene um carácter de regularidad universal.” LOTMAN, Y. La Semiosfera. Vol. I: Semiótica de la cultura y del texto. Madrid: Ediciones Cátedra, série Frónesis, 1996. p. 33-34.

18 “Claramente, a globalização não é um ramo de negócios direto. Ela não é necessariamente linear nem progressiva. Seu desenvolvimento é ao mesmo tempo inconstante, desigual, e gerou enormes disparidades de riqueza e poder, estimulando amplos movimentos de resistência [...] Criou uma cunha entre as 'elites extraterritoriais', a parte da população que tem o poder e a liberdade de movimentar-se e agir através do globo, e a maioria territorializada, 'localizada', deixada para trás em comunidades cada vez mais enfraquecidas, esvaziadas de significado e de recursos (Bauman, 1998) [...] Para alguns, a globalização é o nome ofuscante de uma nova forma de império - o império anônimo de um capitalismo totalmente abrangente, agora mais poderoso e penetrante do que nunca foi no tempo em que os Estados-nações eram os 
atingindo com velocidade e intensidade distintas diferentes fatores sociais. Isso se aplica, guardadas as devidas peculiaridades, tanto às relações sociais no âmbito de um estado como às relações internacionais; tanto ao direito como a outros fatores sociais.

No que concerne às atividades do Banco Mundial ${ }^{19}$, trata-se de tema de extrema riqueza, suscetível às mais diversas abordagens. Numa dimensão mais ampla, são expressões concretas do processo de globalização. Com efeito, muito se critica a ação das Instituições Financeiras Internacionais ${ }^{20}$ (IFIs) como agentes do processo de globalização econômica, esquecendo-se, no entanto, que sua criação objetivava exatamente a realização dessa tarefa. Sob essa perspectiva, essa experiência pode ser considerada como tendo sido muito bem-sucedida.

No âmbito jurídico, o advento das organizações de Bretton Woods constituiu-se numa nova etapa do processo de institucionalização da cooperação internacional. A despeito das críticas que podem ser feitas a algumas escolhas efetuadas em sua concepção, estruturalmente se tratou de entidades inovadoras. Além de seu sistema de voto peculiar (voto ponderado), seus instrumentos operacionais permitiram-lhes exercer influência dificilmente contrastável por outras entidades.

Segundo Saunier, "En droit international, les banques multilatérales ne constituent pas une catégorie juridique aux frontières très sûres. Hormis l'exigence d'un traité à la base de la personnalité juridique internationale de ces organisations, la banque est avant tout une activitê, 21 . Disso, extraem-se ao menos duas conclusões: (a) muito embora o direito seja elemento essencial na composição da estrutura dos bancos multilaterais de desenvolvimento, não se trata do único, tampouco do mais importante elemento de sua composição, fator que não

veículos do capitalismo ou quando os Estados europeus dividiam o mundo entre si." KUMAR, K. Da sociedade pós-industrial à pós-moderna: novas teorias sobre o mundo contemporâneo. Cit., p. 26-27.

${ }^{19}$ Ao longo desse trabalho usar-se-á o termo Banco Mundial ou, simplesmente Banco, para se referir ao Grupo Banco Mundial. Tendo em vista que as demais afiliadas foram criadas apenas num segundo momento, em determinadas circunstâncias, facilmente identificáveis pelo contexto, haverá identidade entre o Banco e o BIRD.

${ }^{20}$ Popularizou-se o emprego da expressão Instituições Financeiras Internacionais (doravante, IFIs) para referir-se às organizações internacionais criadas na Conferência de Bretton Woods: o Fundo Monetário Internacional (FMI) e o Banco Internacional para a Reconstrução e o Desenvolvimento (BIRD), também conhecido como Banco Mundial.

${ }^{21}$ SAUNIER, P. Le système financier et monétaire international. In : HAQUIANI, Z.; SAUNIER, P. Droit international de l'économie. Cit., p. 72. 
impede, no entanto, que abordemos tais entidades segundo a perspectiva jurídica; (b) se esses bancos são, como se propõe, acima de tudo uma atividade, parece impossível reduzir-se o relacionamento entre o banco e o membro à simples relação contratual. Nesse caso, para entendê-lo, deve-se obrigatoriamente retornar a seus propósitos. A despeito de alternativas possíveis, acreditamos que somente uma abordagem de tal amplitude possa revelar a complexidade de suas operações. Para tanto, tentaremos explorar o Banco Mundial em diferentes níveis.

As organizações internacionais são produto do desenvolvimento da cooperação internacional. Dessa forma, para se compreennder o processo histórico e as forças que motivaram a sua criação, além das implicações de sua contínua evolução funcional, parece-nos indispensável tratá-las, o que será feito no capítulo 1, como uma etapa do processo de transformação do direito internacional.

Outra faceta do impacto da globalização na sociedade foi a demanda de respostas mais rápidas e eficazes a problemas urgentes. Frente à habitual rigidez das formas tradicionais de formação do direito internacional, novos instrumentos de natureza um tanto duvidosa foram criados. O transplante da noção de regulação da economia para o direito interno e desse para o direito internacional, abordado no capítulo 2, faz parte desse processo.

A regulação internacional do project finance, focalizada no capítulo 3, consiste, por seu turno, num exemplo bem acabado desse fenômeno. Analisando-o, penetramos num ambiente livre das dicotomias tradicionais (público/privado, interno/internacional), em que entidades das mais diversas naturezas relacionam-se impulsionadas por uma causa comum: a realização do projeto. Nesse ambiente, regulado por ações e normas provenientes de diferentes agentes, o Banco Mundial intervém de maneiras distintas seja como participante, mas como agente regulador.

Diferentemente da parte 1, voltada para o domínio externo, a parte 2 dedica-se ao ambiente interno do Banco. Concebidas ainda durante a guerra, as IFIs logo se revelaram superadas pela velocidade dos acontecimentos. Diante disso, a necessidade de adaptar-se à nova realidade surgiu como um imperativo em vista da ameaça de obsolescência. Como resposta, o Banco evoluiu, seja funcionalmente (capítulo 4), seja 
estruturalmente (capítulo 5), tornando-se um grupo por meio da agregação de outras entidades.

Finalmente, o capítulo 6 será dedicado aos principais instrumentos empregados pelo Banco em suas atividades. Nele, observaremos como a concatenação desses vários elementos conferiu ao Banco poder regulador a princípio inexistente em seu mandato. 


\section{Conclusão}

A elaboração desse trabalho inevitavelmente levou à leitura de vasto material acerca do Banco Mundial, mas não somente. Ao longo desse período, ouviram-se muitas pessoas que, em determinado momento de suas vidas, tiveram algum tipo de ligação mais ou menos duradoura com o Banco. Dentre elas, professores universitários, funcionários governamentais de países-membros, funcionários de carreira do Banco, membros de organizações não governamentais, representantes de paísesmembros alocados na Diretoria Executiva do Banco, ex-diretores aposentados da instituição. Cada um deles (alguns originários de países em desenvolvimento, outros de países desenvolvidos) carrega consigo uma visão peculiar acerca do Banco, forjada não somente por experiências vividas em contato com a instituição, mas também por sua história pessoal e suas convicções políticas. Disso resultaram percepções muitas vezes parciais, nem sempre racionais, mas nunca indiferentes a respeito da organização: chega até mesmo a ser interessante observar alguns deles inflamarem-se ao atacá-1o. Em defesa do Banco, fica a observação que não lhe cabe posicionar-se como substituto de Estados negligentes; seu papel deve ser acessório, não podendo ser o único responsável, como ocorre algumas vezes, pelo fracasso de algumas iniciativas.

Após ouvir relatos tão díspares (não obstante versarem sobre o mesmo objeto), acredita-se que a observação de Mason e Asher sobre a IDA aplica-se mutatis mutandis ao Banco como um todo. Há, realmente, "several different ways of looking at the creation and operation of IDA as an affiliate of the World Bank. Each of these perspectives has some validity, but no one of them alone will suffice ${ }^{22}$. De fato, cada um dos entrevistados apontou um aspecto relevante da organização, contudo nenhuma dessas opiniões, isoladamente considerada, foi capaz de captar com exatidão toda a sua complexidade. Afinal, a imagem que permanece é a de um grande caleidoscópio composto

\footnotetext{
${ }^{22}$ MASON, E. S.; ASHER, R. E. The World Bank since Bretton Woods. Cit., p. 417.
} 
por cores distintas e cujas formas metamorfoseiam-se mediante o efeito do tempo e sob pressões sociais do contexto em que evolui.

Uma dessa cores é certamente o poderoso componente político que anima a instituição pelo interior. Apontam Abbott e Snidal que "powerful states structure such organizations to further their own interests but must do so in a way that induces weaker states to participate" ${ }^{23}$. Nesse sentido, o incontrastável poder de alguns de seus membros pode ser considerado um vetor inigualável na definição do futuro dessas organizações. No entanto, não se constitui na única força a animá-las. A fim de realizar seus propósitos, instituições desse gênero necessitam de clientes, sem os quais toda a sua parafernália de mecanismos, instrumentos e políticas não teria razão de ser. Para obtêlos, suas intenções devem ser (se não, ao menos parecer) genuínas.

As formidáveis transformações ocorridas na sociedade internacional, sobretudo durante a segunda metade do século XX, extinguiram parte considerável do mandato dessas instituições ao mesmo tempo em que lhes lançaram novos desafios. O processo de descolonização deu nova dimensão ao desenvolvimento, propósito remanescente do Banco após equacionada a questão da reconstrução. O avanço da pesquisa, as raízes estruturais do subdesenvolvimento e o alargamento da distância entre países desenvolvidos e em desenvolvimento tornaram a redução da pobreza sua prioridade. Desmunido de instrumentos para alcançar tão grandiosas metas, o Banco confrontou-se à necessidade de se adaptar a essa nova realidade. Para tanto, evoluiu em duas dimensões diversas, porém complementares.

Estruturalmente, a multiplicação de afiliadas dotadas de competências distintas transformou-o num Grupo de instituições. A complementaridade entre essas organizações permitiu ao Banco corrigir alguns problemas originais de concepção, mas acima de tudo equipou-o de forma mais adequada para responder às demandas de um novo mundo, repaginado pelo processo de globalização. No âmbito funcional, o contínuo alargamento de seu mandato, levado a cabo pelo artifício da "interpretação criativa" de seus Estatutos, conferiu-lhe atribuições originalmente

\footnotetext{
${ }^{23}$ ABBOT, K. W.; SNIDAL, D. .Why States act through formal International Organisations. In: Journal of Conflict Resolution. vol. 42, p. 3-32, fev. 1998.
} 
imprevistas. As severas críticas formuladas à forma pela qual se deu essa evolução revelam um processo de corrosão da legitimidade institucional que conheceu o seu ápice nos anos 1990, notadamente com a proliferação de programas de ajuste fundados em políticas neoliberais de valor duvidoso. Os resultados pouco animadores desses programas provocaram o questionamento dessas políticas, sua revisão e a incorporação de novos princípios operacionais que promovessem maior engajamento dos membros na elaboração e execução dos projetos (ownership). Todavia, essa correção de rota não impediu que as bem articuladas críticas à expansão das atividades do Banco expusessem os problemas de legitimidade de sua deriva funcional.

De qualquer maneira, esse processo reconfigurou completamente as feições do Banco. A partir disso, não há como não atribuir razão a Shihata quando afirma que "The World Bank was not envisaged as an instrument for the progressive development of international Law [...]. However, through is broad development mandate the Bank has continually expanded its functions and its understandings of the scope of its possible intervention" 24 . De fato, ampliando o raio de visão, tomando em perspectiva a ação dos bancos multilaterais de investimento e situando-se o Grupo Banco Mundial no centro desse sistema, é inevitável reconhecer que, conquanto não seja o único, trata-se de um poderoso agente regulador, cujas funções foram remodeladas com o tempo à força de sua contínua adaptação aos desafios do cenário internacional. Nesse caso, o fato de não possuir original competência reguladora não o tem impedido de efetivamente regular parcela significativa das atividades econômicas internacionais.

Não obstante constitua-se num ponto central de nosso trabalho, o Banco não é, contudo, o único tema a nos motivar. Numa perspectiva mais ampla, o Grupo Banco Mundial ou, mais precisamente, o papel desempenhado por ele na regulação internacional do project finance é o veículo que nos transporta através das transformações sofridas pelo direito internacional ao longo do último século. Tão importante quanto identificar o Banco como um dos agentes reguladores dessa atividade, sobretudo em

\footnotetext{
${ }^{24}$ SHIHATA, I. F. I. The World Bank in achanging world (vol. III) Cit., p. 514.
} 
projetos situados em países em desenvolvimento, é desvendar como desenvolveu essas atribuições e detectar os mecanismos que emprega na realização dessa tarefa.

As mudanças no direito internacional não são realmente um tema novo, o que não quer dizer que não estejam na ordem do dia. Na realidade, o contínuo movimento de transformação do direito internacional moderno estende-se no tempo. Suas raízes passaram a fortalecer-se à medida que o Estado, elemento estruturador do modelo vestfaliano, perdia sua proeminência. Sucessivas etapas desse processo conduziram-nos à conjuntura atual, em que a multiplicação das normas e organismos internacionais provoca o contínuo esboroamento da linha divisória, nem sempre tão nítida, é verdade, mas outrora mais clara, entre a competência privativa do direito interno e a competência do direito internacional. Na passagem, surgem temores (justificados ou não) quanto à fragmentação de um direito que se expande de maneira aparentemente pouco ordenada.

No entanto, essas mudanças não parecem ter impactado todas as áreas do direito internacional com a mesma intensidade. Em setores particularmente sensíveis aos efeitos da globalização, como o meio ambiente e a economia, o primeiro pela sua natureza intrínseca, o segundo pela interconexão dos mercados, a velocidade das transformações e a profundidade de seus efeitos aparentam maior contundência. Efeito colateral desse processo, a rigidez das formas tradicionais de produção do direito é rapidamente preterida em função de instrumentos inovadores de valor jurídico questionável, entretanto, capazes de oferecer respostas rápidas a necessidades imediatas. Assim, num contexto orientado pelo liberalismo, caracterizado por forte pragmatismo e quase exclusivamente baseado numa opaca noção de efetividade, novas formas de regulação de certas atividades dotadas de impacto internacional foram concebidas.

Importada da economia para o direito interno e desse para o direito internacional, a noção de regulação, a despeito do considerável volume técnico já produzido, não possui no âmbito internacional definição muito clara. Muitas vezes empregada como sinônimo de direito, outras com conotação absolutamente diversa, exibe um pretenso ar de tecnicismo que não se confirma na prática. Pelo que se pôde perceber, apesar da 
banalização de seu uso, não há uma noção, muito menos um conceito definido em direito internacional para esse termo. Neste trabalho, não obstante as vicissitudes decorrentes da importação de um conceito forjado para ser empregado num contexto específico, optou-se por identificar os fatores centrais que caracterizaram a regulação no âmbito interno a partir de experiências vividas por dois sistemas jurídicos diversos. Finalmente, preferiu-se adotar uma noção bastante ampla de regulação, que abarcasse o maior número possível de hipóteses de organização das relações sociais em determinado mercado. A partir disso, a exemplo do que ocorre também no âmbito interno, incluiu-se, além de normas jurídicas, quaisquer intervenções não normativas tendentes a equacionar falhas num determinado mercado. Reconhece-se que tal amplitude conceitual não é isenta de críticas. Ao combinar normas jurídicas e instrumentos desprovidos de força obrigatória, essa noção de fato não contribui para o esforço de classificação das normas jurídicas internacionais. Por outro lado, quer aprovemos ou não, essa escolha reflete com maior precisão a realidade das relações jurídicas nesse setor.

Nesse contexto, a conduta do Grupo Banco Mundial é um terreno fértil para exploração desses novos instrumentos de intervenção. A despeito da sempre presente preocupação do Banco com o respeito ao formalismo jurídico, o contraste entre suas ações e o direito internacional clássico pode ser situado em dois níveis: no âmbito interno, o processo de evolução do Banco desafia a teoria clássica; no externo, impulsiona um processo de formação do direito paralelo às formas tradicionais de produção.

Com efeito, as organizações de Bretton Woods destacam-se por terem sido umas das mais formidáveis criações jurídicas de seu tempo. Todavia, o caráter vanguardista de sua estrutura institucional contrastou com a inspiração ultrapassada que dominou a definição de seus mecanismos internos, esses rapidamente superados pela velocidade dos acontecimentos. No caso do FMI, por exemplo, o sistema de paridades monetárias fixas ajustáveis funcionou de forma efetiva por pouco mais de uma década: de 1958, quando finalmente a Inglaterra e outros países restabeleceram a conversibilidade de suas moedas, a 1973, quando os Estados Unidos abandonaram definitivamente o padrão ouro. Quanto ao Banco, a 
subestimação dos custos da reconstrução e a concorrência de outras iniciativas (e.g. Plano Marshall) suprimiram-lhe o que era considerado o principal de seus propósitos. Com relação ao seu propósito remanescente, o desenvolvimento, as constatações não se revelaram mais animadoras. A assimilação de ambos, sugerindo que a mera transferência de capitais seria suficiente para equacionar tanto os problemas relacionados à reconstrução como aqueles relacionados ao desenvolvimento, demonstra um grande equívoco na identificação da natureza de cada um desses processos. A admiração da direção do Banco ao constatar, no $4^{\circ}$ Relatório Anual do BIRD, “how very undeveloped 'less developed countries' are”, é complementada assim com a resignação, visível já nos anos 1950, de que "Money alone is no solution... Perhaps the most striking single lesson which the bank has learned in the course of its operations is how limited is the capacity of the underdeveloped countries to absorb capital quickly for really productive purposes" ${ }^{\prime 25}$. Confrontados a esse cenário, Banco e Fundo, então guiados por uma espécie de instinto autopreservação, lançaram-se à procura de um novo papel a desempenhar no cenário internacional.

A partir desses dados, é difícil negar a necessidade de efetuar mudanças com a qual o Banco se confrontou. O que se contesta, a esse respeito, não são as justificativas que deram impulso a seu ímpeto reformador, mas a forma pela qual essa evolução funcional ocorreu. Ainda mais porque tais transformações, na prática, acarretaram alterações substanciais em seu mandato.

Dentre as duas alternativas viáveis à expansão funcional da organização, o processo de emenda, embora tecnicamente o mais recomendado, foi preliminarmente afastado devido às dificuldades políticas em que implicava. Não obstante se constituísse em hipótese terminantemente rechaçada pelo Advogado Geral do BIRD, a opção pela via interpretativa, ao menos por um curto período, serviu de sucedâneo ao processo de emenda. Fundada na teoria dos poderes implícitos, essa estratégia expandiu as fronteiras do mandato institucional, desconsiderando as claras limitações impostas pela doutrina ultra vires. Porém, o mais

\footnotetext{
${ }^{25}$ MASON, E. S.; ASHER, R. E. The World Bank since Bretton Woods. Cit., 460-461.
} 
espantoso disso tudo não foi a aplicação muitas vezes irregular desses bem definidos institutos de direito internacional, mas sim a adoção de uma terceira via, um procedimento informal não contemplado nos Estatutos da organização. Foi dessa forma que os empréstimos-programa banalizaram-se e que a condicionalidade atrelada a seus acordos conheceu nítida deriva ideológica, solapando, entretanto (porque ação alguma é imune à causalidade), a legitimidade da instituição ${ }^{26}$.

O segundo cenário em que as ações do Banco constituíram-se em novas manifestações do direito internacional é o externo. Observou-se que as regras internas da organização, algumas meras recomendações, outras normas de vinculação restritas ao staff, à força de serem incorporadas a seus acordos financeiros passaram também a produzir efeitos e a condicionar condutas externas, revelando, ao menos no caso do Banco, as fragilidades práticas da separação entre normas internas e externas da organização ${ }^{27}$. Isso tudo sem mencionar o déficit democrático presente em sua elaboração. Nesse contexto, dois processos devem ser destacados.

No que concerne às práticas do Banco, elaborou-se um sofisticado mecanismo por meio do qual as pesquisas técnicas assumem a forma de planos de ação, esses são consolidados em regras internas, e essas regras são incorporadas a seus acordos financeiros sob o formato de condições. Individualizada cada uma dessas etapas, dificilmente atribuir-se-á valor normativo às políticas preconizadas pelo Banco, tampouco poder regulador à instituição. Apreendidas cada uma delas como engrenagens interdependentes de um mecanismo mais amplo, tem-se os contornos de um poderoso instrumento jurídico dotado de força obrigatória e meios de sanção bastante efetivos, capazes de lhe garantir níveis de implementação próximos (quando não até mesmo superiores) àqueles apresentados pela legislação interna.

O alcance das políticas preconizadas pelo Banco não se reduz, todavia, à esfera individual. A reputação ${ }^{28}$ que adquiriu como centro de

\footnotetext{
26 "Conditionality - including the manner in which conditions have often been imposed - has come to be seen by many, especially within the developing world, as part of the new economic colonialism which has succeeded the old." STIGLITZ, J. E. Introduction. In: The World Bank: structure and policies. Cit., p. 4.

${ }^{27}$ BROCHES, A. International legal aspects of the operations of the World Bank. Cit., p. 302.

${ }^{28}$ Cf. BAUMAN, Z. Identidade: Entrevista a Benedetto Vecchi. Rio de Janeiro: Jorge Zahar, 2005.
} 
excelência em matéria de desenvolvimento credencia-o a elaborar fórmulas e conceitos que, repetidos à exaustão e absorvidos pela sociedade internacional e pelo mercado, acabam adquirindo "ares" de normas costumeiras. Consolidadas em declarações, guidelines, "manuais de boas práticas", enfim, numa série de documentos rotulados sob o controvertida nomenclatura soft law, tais recomendações sedimentam o terreno em áreas nas quais as dificuldades de se alcançar o consenso impedem a formação de regras internacionais mediante o emprego de processos tradicionais (hard law). Nesses casos, são muitas vezes identificadas como uma etapa preliminar no processo de formação do direito, por meio de convenções multilaterais ou, o que se tem tornado habitual, da consolidação de costume internacional ${ }^{29}$.

Em tempos mais recentes, uma nova forma de emprego do soft law distinta das acima apontadas tem sido observada. Diante da crescente resistência dos países a comprometerem-se formalmente perante a ordem internacional, condutas têm sido harmonizadas no âmbito global por instrumentos supostamente desprovidos de força obrigatória e depois internalizadas de forma unilateral pelas legislações nacionais. A prática brasileira constitui-se num exemplo marcante dessa prática. Por exemplo, sua reticência em firmar acordos de investimento não impediu o país de reproduzir em sua Carta Constitucional dois dos pilares do direito internacional dos investimentos: o tratamento nacional ${ }^{30}$ e a garantia de pagamento de justa indenização em caso de expropriação ${ }^{31}$. Independentemente das discussões relativas à real autonomia dos países face ao direito internacional quando adotam tal prática, é inevitável reconhecer que se trata de uma forma paralela de regulação das atividades

\footnotetext{
29 "As a consequence, the standards, statements, and other instruments at issue do not impose legally binding obligations. Nevertheless, these matters, although they remain legally unregulated, become the object of agreed guidelines, or statements of common positions or policies. These may thus lay the ground, or constitute the building blocks, for the gradual formations of customary rules or treaty provisions. In other words, gradually 'soft law' may turn into law proper.” CASSESE, A. International law, Cit., p. 196.

30 "Art. $5^{\circ}$, caput: Todos são iguais perante a lei, sem distinção de qualquer natureza, garantindo-se aos brasileiros e aos estrangeiros residentes no País a inviolabilidade do direito à vida, à liberdade, à igualdade, à segurança e à propriedade, nos termos seguintes." BRASIL. Constituição da República Federativa do Brasil de 1988. Disponível em: 〈http://www.planalto.gov.br/ccivil_03/constituicao/constituicao.htm〉. Acesso em: 30 dez. 2012.

31 "Art. $5^{\circ}$, XXIV: a lei estabelecerá o procedimento para desapropriação por necessidade ou utilidade pública, ou por interesse social, mediante justa e prévia indenização em dinheiro, ressalvados os casos previstos nesta Constituição." Idem.
} 
internacionais diretamente concorrente com as formas tradicionais de formação do direito.

Em síntese, realizando-se por intermédio de instrumentos jurídicos, mas também por meio de outras formas menos ortodoxas de natureza ainda não consolidada, a ação do Banco parece dar algumas amostras do que poderá vir a ser a próxima etapa de evolução do direito internacional (ou, ao menos, de parte dele). Nesse contexto, a contínua expansão das atividades das organizações internacionais sugere que nos conduzimos a um caminho sem volta no processo de elaboração do direito internacional. Todavia, o resultado dessa transformação ainda é incerto, em especial diante do que alguns defendem ser o ressurgimento do Estado. De um lado, a crise econômica nos países desenvolvidos, de outro, a premência de algumas questões fundamentais, como o meio ambiente, têm imposto às autoridades nacionais maior energia no tratamento de algumas questões. Paralelamente, observa-se o surgimento de um novo modelo de Estado empresário, especialmente popular em algumas economias emergentes. Em termos concretos, tais fenômenos podem exigir certa adaptação do direito internacional dos investimentos. O crescente endividamento de algumas economias desenvolvidas pode levar, segundo alguns analistas, à redução da amplitude da definição do termo "investimento" nos tratados bilaterais. Ao mesmo tempo, o caráter transversal e o intrincamento cada vez maior de alguns temas (e.g. meio ambiente e economia) demandam uma abordagem cada vez abrangente desses fenômenos. Shihata sugere que "The experience of ICSID has already shown that its facilities for the resolution of investment disputes may be used for the settlement of environmental disputes arising out of foreign investment [...] This could also lead to an increase in the number of ICSID cases initiated by host countries $^{\prime 32}$. No que concerne às empresas controladas pelo Estado, questiona-se se a cláusula de segurança nacional é suficiente, ou apropriada, para impedir o seu avanço. Finalmente, frente à crescente sofisticação do direito internacional dos investimentos, chega-se mesmo a

\footnotetext{
${ }^{32}$ SHIHATA, I, F. I. The World Bank in a Changing World. Cit., vol. III, p. 796.
} 
indagar se o poder de regular corre riscos ${ }^{33}$. Num cenário de tantas dúvidas, uma das poucas certezas que permanece é que o direto continuará a evoluir, pois a exemplo de qualquer fator social ele inexoravelmente sofre os efeitos do tempo e do ambiente em que se insere.

Também com relação ao Banco (instituição), parece-nos extremamente difícil antever como responderá às transformações do cenário internacional. A globalização segue a sua marcha e, em sua passagem, os problemas adquirem nova complexidade. A intensificação da mobilidade, uma faceta desses novos desafios, tem criado sérias dificuldades à gestão dos serviços públicos. Na Europa, por exemplo, um contingente populacional cada vez maior de imigrantes ilegais encontra-se sem saída numa espécie de no man's land social entre as crescentes restrições ao acolhimento de imigrantes impostas pelos países do bloco e as reconhecidas deficiências estruturais de seu Estado de origem.

Por outro lado, a atual crise econômica tem ampliado a pobreza em regiões em que ela não se constituía de fato num problema. Na Espanha, segundo o Instituto Nacional de Estatística, $21 \%$ da população era classificada como pobre em meados de 2011, um crescimento de $50 \%$ se comparado com $1991^{34}$. Nos Estados Unidos, o número pessoas sem-teto cresce assustadoramente, atingindo com particular intensidade a população jovem ${ }^{35}$. Ao mesmo tempo, em regiões pobres do globo, repetem-se situações recorrentes de pobreza extrema, aceleradas pela crise global: a globalização da crise parece ter reflexamente globalizado a pobreza.

Outro tema a que o Banco deverá se dedicar com ainda mais vigor é o meio ambiente. Outrora tido como um malabarismo interpretativo, a identificação da questão ambiental nos Estatutos do Banco encontra hoje respaldo em dados concretos. De acordo com o Relatório sobre o

\footnotetext{
${ }^{33}$ PAULSSON, J. Indirect expropriation: is the right to regulate at risk? In: Making the most of international agreements: a common agenda. Simpósio Co-organizado por ICSID, OECD e UNCTAD. Paris: OECD Headquarters, 12 de dezembro de 2005.

${ }^{34}$ INFANTE, A. Crise cria novos pobres na Espanha. Artigo publicado no website da BBC em 16 de agosto de 2011.2 Disponível em: <http://www.bbc.co.uk/portuguese/noticias/2011/08/110815_espanha_pobres1_pu.shtml〉. Acesso em: 13 jan. 2012.

${ }^{35}$ SAULNY, S. After recession, more young adults are living on street. Artigo publicado no website do New York Times, 18 de dezembro de 2012. Disponível em: <http://www.nytimes.com/2012/12/19/us/sincerecession-more-young-americans-are-homeless.html?pagewanted=all>. Acesso em: 13 jan. 2013.
} 
Desenvolvimento no Mundo de 2010, apesar de se tratar de um fenômeno global, as mudanças climáticas atingirão com maior intensidade os países em desenvolvimento. A multiplicação de tempestades poderá causar impactos climáticos catastróficos e irreversíveis, especialmente em zonas costeiras. Segundo projeções do próprio Banco, a despeito dos esforços empreendidos no combate à fome nas últimas décadas ${ }^{36}$, as mudanças climáticas proporcionarão um acréscimo de 100 a 400 milhões de pessoas famintas no mundo; a carência de água passará a ser um problema para um número ainda maior de pessoas ${ }^{37}$. Devido à forte dependência da exploração de recursos naturais e ao fato de parte substancial de suas populações viver em zonas expostas a riscos naturais, os países em desenvolvimento certamente suportarão os maiores prejuízos. Calcula-se que $75 \%$ a $80 \%$ dos custos decorrentes das mudanças climáticas recairão sobre esses países. Mais concretamente, o esperado aumento de no mínimo $2^{\circ} \mathrm{C}$ da temperatura causará uma contração do consumo por habitante na África e no sudeste da Ásia da ordem de $4 \%$ a 5\%, valores significativos se considerarmos que o consumo mundial médio por habitante se retrairá apenas $1 \%$. Na prática, haverá um alargamento da distância já abissal entre países desenvolvidos e em desenvolvimento.

Sem mencionar outros problemas com os quais será confrontado, parece-nos que, não obstante a sua evolução, o Banco não está preparado para enfrentar o cenário que se anuncia. Indubitavelmente continuará a avançar, criando novos instrumentos de ação, mas passados quase 70 anos de sua criação, as bases sobre as quais foi edificado não passam hoje de referência histórica. O anacrônico sistema de voto ponderado confere-lhe um viés político absolutamente inadequado tendo em vista as suas aspirações globais. Por conta disso, alguns países em desenvolvimento (e.g. China, Brasil, Índia) não somente deixaram de ser clientes do Banco, mas

\footnotetext{
${ }^{36}$ Há 30 anos metade da população mundial vivia em situação de pobreza extrema; hoje essa proporção é de 1/4. No entanto, as necessidades permanecem enormes: o número de pessoas que sofrem com fome ultrapassou, pela primeira vez, o bilhão em 2009.

37 "Á long terme, les changements climatiques représentent une menace grave pour le développement de l'humanité et à certains endroits ils mettent déjà en danger les efforts déployés par la communauté internationale en vue de réduire de la pauvreté extrême." NAÇÕES UNIDAS (PNUD). Rapport Mondial sur le développement humain 2007-2008: La lutte contre le changement climatique: un impératif de solidarité humaine dans un monde divisé. Disponível em: http://hdr.undp.org/en/media/HDR_20072008_FR_Complet_rev.pdf. Acesso em 13 de janeiro de 2013.
} 
tornaram-se seus concorrentes por meio da intensificação da cooperação bilateral sul-sul. Da mesma forma, o avanço das técnicas e instrumentos de governança (accountability), inclusive com a participação da sociedade civil, transformaram a fórmula projeto específico/fins produtivos em uma limitação desnecessária. Finalmente, as recentes crises econômicas expuseram uma questão filosófica essencial: o capitalismo não se presta a resolver inúmeros problemas relacionados ao subdesenvolvimento. Aliás, disfunções do capitalismo são uma das causas de muitos dos problemas que o Banco se propõe a corrigir. Nesse sentido, se tinha razão Hobsbawm ao professar que a economia capitalista "está entrando em colapso diante de nossos olhos" ${ }^{\text {, }}$, cabe ao Banco reinventar-se, sob pena de, não o fazendo, tornar-se irrelevante.

${ }^{38}$ HOBSBAWM, E. J. Socialism has failed. Now capitalism is bankrupt. What comes next? In: The Guardian, 10 de abril de 2009. Versão em língua portuguesa publicada pela Folha de São Paulo em 06 de outubro de 2012. Disponível em: <http://www1.folha.uol.com.br/ilustrada/1162270-hobsbawn-o-socialismofracassou-agora-o-capitalismo-faliu-o-que-vira-a-seguir.shtml>. Acesso em: 13 jan. 2013. 


\section{Bibliografia}

- ABI-SAAB, Georges. "Éloge du 'droit assourdi' quelques réflexions sur le rôle de la soft law en droit international contemporain »(in Nouveaux itinéraires en droit - hommage à François Rigaux : Mélanges Rigaux, Bruxelas: Bruylant, 1993).

- ABBOT, Kenneth W. ; SNIDAL, Duncan. «Why States act through formal International Organisations» (in Journal of Conflict Resolution, vol. 42, Fev./1998, pp. 3-32).

- ACCIOLY, Hildebrando; NASCIMENTO E SILVA, Geraldo E.; CASELLA, Paulo B. Manual de direito internacional público. São Paulo: Saraiva, 2010.

- AGO, Roberto. «Communauté internationale et organisation internationale » (in Manuel sur les organisations internationales - a handbook on international organizations, Dordrecht; Boston; Lancaster: Martinus Nijhoff Publisheurs, 1998).

- ALLAND, Denis (org.).Droit international public. Paris : Presses Universitaires de France, 2000.

- ALVAREZ, Jose Enrique. International Organizations as Law-makers. New York: Oxford University Press, 2006.

- ALVAREZ, Jose Enrique. International organizations: then and now (in American Journal of International Law: volume 100, Washington: American Society of International Law, abril 2006 - p. 324-347)

- ALVAREZ, Jose Enrique. The public international law regime governing international investment (RCADI-2009, T. 344, pp. 193-544).

- ALVES, José Carlos Moreira. Direito Romano. Rio de Janeiro: Forense, 2008.

- AMARAL, Francisco. Direito Civil: Introdução. Rio de Janeiro: Renovar, 2006.

- AMARAL JUNIOR, Alberto do. A solução de controvérsias na OMC. São Paulo: Atlas, 2008.

- AMERASInGHE, Chittharanjan Felix. Principles of the Institutional Law of International Organizations. Cambridge, UK: Cambridge University Press, 2005.

- ANGliettA, Michel (org.). Cinquante ans après Bretton Woods. Paris: Economica, Coll. CEPII, 1995. 
- ANZILOTTI, Dionisio. Cours de droit international. Paris : Panthéon Assas, 1999.

- ASSIDON, Elsa. Les théories économiques du développement. Paris, La Découverte, Coll. Repères, 2000.

- BABB, Sarah. Behind the development banks: Washington politics, world poverty, and the wealth of nations. Chicago: The University of Chicago Press, 2009.

- BALANDA, Jacques Bertrand de. «Crédit syndiqué et sûretés» (in Revue Banque et Droit - $\mathbf{n}^{\circ}$ 52, Paris: março/abril 1997)

- BANDEIRA DE MELlO, Celso Antonio. Elementos de direito administrativo. São Paulo: Malheiros editores, 1992.

- BAUMAN, Zygmunt. Globalização: as conseqüências humanas. Rio de Janeiro: Jorge Zahar Ed., 1999.

- BAUMAN, Zygmunt. Identidade: Entrevista a Benedetto Vecchi. Rio de Janeiro: Jorge Zahar Ed., 2005.

- BAUMAN, Zygmunt. Modernidade líquida. Rio de Janeiro: Jorge Zahar Ed., 2001.

- BECK, Ulrich. O que é Globalização? equívocos do globalismo: respostas à globalização. São Paulo: Terra e Paz, 1999.

- BECK, Ulrich. Sociedade de risco: Rumo a uma outra modernidade. São Paulo: Ed. 34, 2010.

- BECK, Ulrich; GIDDENS, Anthony; LASH, Scott. Modernização reflexiva: política, tradição e estética na ordem social moderna. São Paulo: Editora das Universidade Estadual Paulista, 1997.

- BELLIS, Marc. «La subordination et les marchés financiers internationaux» (in Prêts participatifs et prêts subordonnés: un nouveau mode de financement, Paris: FEDUCI, 1983)

- BÉNICHOU, Ivan; CORCHIA David. Le financement de projets: Project finance. Paris: Eska, 1996.

- BENOIT, Philippe. «Project finance at the World Bank - an overview of policies and instruments» (World Bank technical paper 312, Washington: World Bank, 1996) 
- BERSTEIN, Serge; MILZA, Pierre (org.). História do Século XX: Vol. I: 19001945, o fim do “mundo europeu”. São Paulo: Companhia Editora Nacional, 2007.

- BERTRAND, René; et al. Les banques de développement dans le monde (vol II). Paris : Dunod, 1965

- BETTATI, Mario. «Création et personnalité juridique des organisations internationales » (in Manuel sur les organisations internationales - a handbook on international organizations, Dordrecht; Boston; Lancaster : Martinus Nijhoff Publisheurs, pp. 33-60, 1998)

- BEVILAQUA, Clovis. Direito Civil dos Estados Unidos do Brasil (vol. I). Rio de Janeiro: Livraria Francisco Alves, 1944

- BIELSCHOWSKY, Ricardo. Cinquenta anos de pensamento na CEPAL. Rio de Janeiro: Record, 2000.

- BISHOP, R. Doak; CRAWFORD, James ; REISMAN, W. Michael. Foreign Investment Disputes: Cases, Materials and Commentary. Haia: Kluwer Law International, 2005.

- BITTERMAN, H. J. «Negotiation of the Articles of Agreement of the International Bank for Reconstruction and Development» (in International Lawyer, vol. 5, $\mathrm{n}^{\circ} 1$, 1971)

- BIZAGUET, Armand; et al. Les banques de développement dans le monde (vol I). Paris : Dunod, 1964

- BLÉMONT, Patrice. «Le partenariat public-privé 'à la source’» (in Bulletin juridique des contrats publics $-\mathbf{n}^{\circ} 38$, Paris: EFE)

- BOHRER, Carolina Pancotto. Promoção do desenvolvimento e rule of law no Banco Mundial. Tese apresentada para obtenção do título doutor em direito internacional. Faculdade de Direito da Universidade Federal de Santa Catarina, 2009.

- BORDO, Michael D.; EICHENGREEN, Barry J. «The rise and fall of barbarous relic: the role of the gold in the international monetary system» in NBER Working Paper (n. 6436). Cambridge, MA: NBER, 1998. Disponível em: http://www.nber.org/papers/w6436. Acesso em 06.08.2010.

- BORGES, Luiz Ferreira Xavier. «Covenants - Instrumento de garantia em Project finance » (in Revista de direito bancário e do mercado de capitais - ano 2, $\mathbf{n}^{\circ}$ 5), São Paulo: Editora Revista dos Tribunais, maio-agosto/1999, pp. 123-135) 
- BOUGHTON, James M. Silent revolution: the International Monetary Fund, 1979 - 1989. Washington: FMI, 2001.

- BOUGHTON, James M. «The IMF and the force of history: Ten events and Ten ideas that have shaped the institution» (in IMF Working Paper 04/75. Washington: FMI, 2004)

- BOURGUINAT, Henri. Finance internationale. Paris: PUF, 1999.

- BOUTMY, Emile. Études de droit constitutionnel. Paris: Plon,1888. Versão digital disponível em: http://archive.org/stream/tudesdedroitcon01boutgoog\#page/n105/mode/2up. Último acesso em : 13 de janeiro de 2013.

- BOYER, Robert. «Les mots et les réalités » (in La mondialisation au-delà des mythes. Paris: La Découverte, 2000).

- BRIERLY, James Leslie. Direito Internacional. Lisboa: Fundação Calouste Gulbekian, $4^{\text {a }}$. Ed., 1979.

- BROCHES, Aron. International legal aspects of the operations of the World Bank (RCADI-1959-III, T. 98, pp. 297-409)

- BROWNLIE, Ian. International law at the fiftieth anniversary of the United Nations (RCADI-1995, T. 255, pp. 9-228).

- BROWNLIE, Ian. Principles of public international law. Oxford: Oxford University Press, 2003.

- BUIRA, Ariel. «The Bretton Woods institutions: governance without legitimacy?» (in CSGR Working Paper $\mathbf{n}^{\circ} \mathbf{1 8 0 / 0 5}$, University of Warwick, Coventry, UK, novembro de 2005)

- BUTLER, William. E. (org.). International law and international system, Dordrecht: Martinus Nijhoff Publishers, 1987.

- CAMINHA, Uinie. Securitização. São Paulo: Editora Saraiva, 2005.

- CAMPILONGO, Celso. «Teoria do direito e globalização econômica» (in Direito Global, São Paulo: Max Limonad, 1999)

- CANOTILHO, José Joaquim Gomes. Direito Constitucional. Coimbra: Almedina, 1993.

- CARR, Eward Hallet. The twenty years' crisis, 1919-1939. New York: Perennial (HarperCollins Publishers), 2001. 
- CARREAU, Dominique. Le Fonds Monétaire International. Paris: Armand Colin, 1970.

- CARREAU, Dominique ; JUILLARD Patrick. Droit international économique. Paris: LGDJ, 1998.

- CASELLA, Paulo B. Direito internacional dos espaços. São Paulo: Atlas, 2009.

- CASELlA, Paulo B. Fundamentos do direito internacional pós-moderno. São Paulo: Quartier Latin, 2008.

- CASELLA, Paulo B. «Modalidades de harmonização, unificação e uniformização do direito - o Brasil e as convenções interamericanas de direito privado» (in Integração Jurídica Interamericana: As convenções interamericanas do direito internacional privado (CIDIP's) e o direito brasileiro, São Paulo: Ltr, 1998).

- CASELLA, Paulo B. Tratado de Versalhes na história do direito internacional. São Paulo: Quartier Latin, 2007.

- CASSESE, Antonio. International law. Oxford: Oxford University Press, 2005.

- CASTELLS, Manuel. A sociedade em rede. São Paulo: Paz e Terra, 2011.

- CAUSSAIN, Jean-Jacques ; MERCADAL Barthélémy (Org.). Prêts participatifs et prêts subordonnés: un nouveau mode de financement: Journée d'étude de Rouen du 19 novembre 1981. Paris: FEDUCI, 1983.

- CHEVAlLIER, Jacques. «La régulation juridique en Question» (in Droit et Société n 49, 2001, p. 827-846)

- CHEVAlLIER, Jacques. «L'état régulateur» (in Review Française de d'administration publique $\mathrm{n}^{\circ} 111,2004 / 3$, p. 473-482). Disponível em < http://www.cairn.info/article.php?ID_REVUE=RFAP\&ID_NUMPUBLIE=RFAP

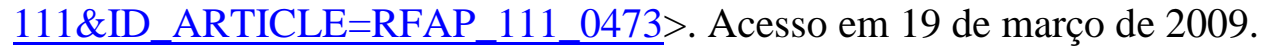

- CLIFFORD CHANCE. Project Finance. London: IFR Publishing, 1991

- COASE, Ronald. Le coût du droit. Paris: Albin Michel, Coleção Le Livre de Poche, 2004.

- COMTE-SPONVILLE, André. Le capitalisme est-il moral?. Paris: PUF, Coleção Droit, Éthique, Société, 2000.

- COSTA, José Augusto Fontoura. Direito internacional do investimento estrangeiro. Tese apresentada para obtenção do título de livre docente de direito internacional. Faculdade de Direito da Universidade de São Paulo, 2008. 
- CRETELLA NETO, José. «Da responsabilidade internacional das organizações internacionais» (in Novas perspectivas do direito internacional contemporâneo - Estudos em homenagem ao Professor Celso D. de Albuquerque Mello, Carlos Alberto Menezes Direito, Antonio Augusto Cançado Trindade, Antonio Celso Alves Pereira (org). Rio de Janeiro: Renovar, 2008)

- DALlARI, Adilson de Abreu ; BRANCO, Adriano Murgel. O financiamento de obras e serviços públicos. São Paulo: Paz e Terra, 2006.

- DAVID, René. Os grandes sistemas do direito contemporâneo. São Paulo: Martins Fontes, 2002.

- D'ARVISENET, Philippe ; PETIT, Jean-Pierre. Economie internationale - La place des banques. Paris: Dunod, 1999.

- DEFARGES, Philippe Moreau. La mondialisation. Paris : PUF, 2002.

- DELLA GASPERA, S. «Trente ans de déréglementation financière » (In Bourse et Marchés Financiers, Cahiers Français, n 301, mar./abr. 2001, p. 64-72)

- DELMAS-MARTY, Mireille. Por um direito comum. São Paulo: Martins Fontes, 2004.

- DELMON, Jeffrey. «Partnership in infrastructure: sorting out the forest from the trees: BOT, DBFO, DCMF, concession, lease... » (in Policy Research Working Paper 5173, Washington, The World Bank Finance and Guarantees Unit, Finance Economics \& Urban Department, Janeiro de 2010). Disponível em: http://wwwwds.worldbank.org/external/default/WDSContentServer/IW3P/IB/2010/01/11/0001 58349_20100111150559/Rendered/PDF/WPS5173.pdf. Acesso em 03 de outubro de 2012

- DELMON, Jeffrey. Project Finance, BOT Projects and Risk. The Hague: Kluber Law International, 2005.

- DELUPIS, Ingrid. «The Legal value of recommendations of international organizations » (in International law and international system, Dordrecht, Martinus Nijhoff Publishers, 1987, pp. 47-65)

- DE VISSCHER, Charles. Cours général de principes de droit international public (RCADI-1954-II, T. 86, pp. 445-556).

- DE VISSCHER, Charles. Theory and reality in Public International Law. New Jersey: Princeton University Press, 1957. 
- DHONTE, Pierre. «Conditionality as an instrument of borrower credibility» (in IMF Paper on Policy Analysis and Assessment - PPAA/97/2, Washington, IMFAfrican Department, 1997)

- DIEZ DE VELASCO VALLEJO, Manuel. Les organisations internationales. Paris: Economica, Collection Droit International, 2002.

- DJILAS, Milovan. Conversations with Stalin. New York: Harcourt, Brace \& Company, 1962.

- DIMATTEO, Larry A. The law of International business Transactions. Mason. Ohio: Thomson/ South-Western West, 2003.

- DINH, Nguyen Quoc ; DAILLIER, Patrick ; PELLET, Alain. Droit international public. Paris: L.G.D.J., 2002.

- DIREITO, Carlos Alberto Menezes; TRINDADE, Antonio Augusto Cançado; PEREIRA, Antonio Celso Alves (org.). Novas perspectivas do direito internacional contemporâneo - Estudos em homenagem ao Professor Celso D. de Albuquerque Mello. Rio de Janeiro: Renovar, 2008)

- DOLINGER, Jacob. Direito internacional privado (Parte especial): (vol. II) contratos e obrigações no direito internacional privado. Rio de Janeiro: Renovar, 2007.

- DOLZER, Rudolf; SCHREUER Christoph. Principles of International Investment Law. New York: Oxford University Press, 2008.

- DROUIN, Michel. Le financement du développement. Paris : Armand Colin, Coll. Synthèse, 1998.

- DROUIN, Michel. Le système financier international. Paris, Armand Colin, 2001.

- DUFOUR, Jean-François. Les marchés émergents. Paris: Armand Colin, Coll. Synthèse, 1999.

- DUFOUR, Jean-Louis. Les décolonisations de 1945 à nos jours. Paris: Armand Colin, 2000.

- DUNCAN, Alex. «The World Bank as a Project Lender» (in The World Bank: its first half century, vol. 2: perspectives. Washington: Brookings Institution Press, 1997) 
- DUPONT, Christophe. «Les institutions internationales bancaires de financement $d u$ développement » (in Les banques de developpement dans le Monde - v. 1, Paris : Dunod, 1964, pp. 67-239)

- DUPUY, Pierre-Marie. Droit international public. Paris: Dalloz, 2004.

- DUPUY, Pierre-Marie. L'unité de l'ordre juridique international (RCADI-2002, T. 297, pp. 9-489).

- DUPUY, Pierre-Marie. «Un Débat Doctrinal à l’Ere de la Globalisation: Sur la Fragmentation du Droit International » (in European Journal of Legal Studies, Vol. 1). Disponível em: http://www.ejls.eu/1/4FR.pdf. Acesso em: 08/06/2011

- DUPUY, René-Jean. Communauté internationale et disparités de développement (RCADI-1979-IV, T. 165, pp. 9-232).

- DUPUY, René-Jean (org.). Manuel sur les organisations internationales: a handbook on international organizations. Dordrecht ; Boston ; Lancaster: Martinus Nijhoff Publisheurs, 1998.

- DUPUY, René-Jean. Le droit internacional. Paris: PUF, 2004.

- DUPUY, René-Jean. «État et organisation internationale » (in Manuel sur les organisations internationales: a handbook on international organizations. Dordrecht ; Boston ; Lancaster, Martinus Nijhoff Publisheurs, pp. 13-30, 1998)

- ECONOMIDÈS, Constantin. «Les actes institutionnels internationaux et les sources du droit international » (in Annuaire Français de Droit International Tome XXXIV, Paris : CNRS, 1988)

- EICHENGREEN, Barry J. A globalização do capital: uma história do sistema monetário internacional. São Paulo: Ed. 34, 2000.

- EICHENGREEN, Barry J., KENEN Peter B. «L'organisation de l'économie internationale depuis Bretton Woods : un panorama» (in Cinquante ans après Bretton Woods, Paris: Economica, Coll. CEPII, 1995, pp. 11-54)

- EICHENGREEN (Barry J.), TEMIN (Peter). "The gold standard and the great depression" in NBER Working Paper (n. 6060). Cambridge, MA: NBER, 1997. Disponível em: 〈http://www.nber.org/papers/w6060. Acesso em 06.08.2010> Último acesso em 13 de janeiro de 2013.

- EISEMANN, Pierre Michel. «Le Gentlemen's agreement comme source du droit international» (in Journal du droit international - vol. 106, $\mathbf{n}^{\circ} \mathbf{2}, 1979$, pp. 326348 
- ENEI, José Virgílio Lopes. Project Finance: financiamento com foco em empreendimentos: (parcerias público-privadas, leveraged buy-outs e outras figuras afins). São Paulo: Saraiva, 2007.

- FABOZZI, Frank J.; DAVIS, Henry A.; CHOUDHRY, Moorad. Introduction to Structured Finance. New Jersey: John Wiley \&Sons, Inc., 2006.

- FENWICK, Charles G. The progress of International law during the past forty years (RCADI-1951-II, T. 79, pp. 1-71).

- FERGUSON, Niall. The ascent of money: a financial history of the world. New York: The Penguin Press, 2008.

- FERREIRA, F. H. G.; KEELY, L. C. «The World Bank and Structural Adjustment: lessons from the 1980» ( in The World Bank: Structure and policies, Cambridge: Cambridge University Press, 2000, pp. 159-189)

- FINNERTY, John D. Project finance - engenharia financeira baseada em ativos. Rio de Janeiro: Qualitymark, 1999.

- FITZMAURICE, Gerald. The general principles of international law considered from the standpoint of the rule of law (RCADI-1957-II, T. 92, pp. 1-227).

- FOLLIOT-LALLIOT, Laurence. «La globalisation du droit des marchés publics » (in Bulletin juridique des contrats publics $-\mathbf{n}^{\circ}$ 39, Paris: EFE)

- FRIEDMAN, Irving S. «Private Bank Conditionality: Comparison with the IMF and the World Bank » (in IMF Conditionality, Washington: Institute for International Economics, 1983).

- FRIEDMAN, Samy. Expropriation in International Law. London: Stevens, 1953.

- FRIEDMANN, Wolfgang. Mudança da estrutura do direito internacional. Rio de Janeiro: Freitas Bastos, 1964.

- FUKUYAMA, Francis. State building - gouvernance et ordre du monde au XXI siècle. Paris : La Table Ronde, 2005.

- FUKUYAMA, Francis. The end of history and the last man. New York: Perennial (HarperCollins Publishers), 2002.

- FURTADO, Celso. «Desenvolvimento e subdesenvolvimento» (in Cinqüenta anos de pensamento na CEPAL - volume I. Rio de Janeiro: Record, 2000. p. 239-262)

- GILBERT, Christopher L.; VINES, David (Org.). The World Bank: structure and policies. Cambridge: Cambridge University Press, 2000. 
- GINTIS, Herbert; et al. Moral sentiments and material interests: the foundations of cooperation in economic life. Cambridge, Massachusetts: MIT Press, 2005.

- GLAESER, Edward. L.; SHLEIFER, Andrei. «The rise of the Regulatory State » (in Journal of Economic Literature, XLI, Jun. 2003, p. 401-425). Disponível em <http://www.economics.harvard.edu/faculty/shleifer/files/rise_reg_state.pdf.> Último acesso em 13 de janeiro de 2013.

- GOLD, Joseph. «Conditionality» (in Pamphlet series $\mathbf{n}^{\circ}$ 31, Washington: FMI, 1979).

- GOLD, Joseph. Legal and institutional aspects of the international monetary system: selected essays (vol. 1 e 2). Washington: FMI, 1979.

- GOLD, Joseph. «The legal character of the Fund's stand-by arrangements and why it matters» (in Pamphlet series $\mathbf{n}^{\circ}$ 35, Washington: FMI, 1980).

- GOMES, Orlando. Introdução ao direito civil. Rio de Janeiro: Forense, 1991.

- GRAU, Eros Roberto. Direito posto e direito pressuposto. São Paulo: Malheiros, 2008.

- GROSS, Leo. «The peace of Westphalia : 1648-1948» (in The American Journal of International Law, Vol. 42, $\mathrm{n}^{\circ}$ 1, Janeiro/1948, pp. 20-41). Disponível em: http://www.jstor.org/stable/2193560. Acesso em: 03/11/2010

- GUGGENHEIM, Paul. Contribution à l'histoire des sources du droit des gens (RCADI-1958-II, Vol. 94, pp. 1-84).

- GUITIAN, Manuel. "The unique nature of the responsibilities of the International Monetary Fund"' (in Pamphlet series n. 46, Washington: FMI, 1992).

- HANDL, Günther. Multilateral Development Banking: Environmental principles and concepts reflecting general international law and public policy. The Hague; London; Boston: Kluwer Law International, 2001.

- HAQUIANI, Zalmaï; SAUNIER, Philippe. Droit international de l'économie. Paris : Ellipses Editions, 2007.

- HASS, Larry; MAZZEI, Leonardo; O'LEARY, Donal. «Setting standards for communication governance - the example of infrastructure projects» (in World Bank working paper $\mathbf{n}^{\circ}$ 121, Washington: 2007)

- HENKIN, Louis. International Law: politics, values and functions (RCADI1989-IV, T. 216, pp. 9-416). 
- HOBSBAWM, Eric J. A era das revoluções: 1789-1848. São Paulo: Paz e Terra, 2010.

- HOBSBAWM, Eric J. A era do capital: 1848-1875. São Paulo: Paz e Terra, 2010.

- HOBSBAWM, Eric J. A era dos impérios: 1875-1914. São Paulo: Paz e Terra, 2010.

- HOBSBAWN, Eric J. Era dos extremos: o breve século XX: 1914-1991. São Paulo: Companhia das letras, 2008.

- HOBSBAWM, Eric. «Socialism has failed. Now capitalism is bankrupt. What comes next?», (in The Guardian, 10 de abril de 2009). Versão em língua portuguesa republicada pela Folha de São Paulo em 06 de outubro de 2012. Disponível em: http://www1.folha.uol.com.br/ilustrada/1162270-hobsbawn-osocialismo-fracassou-agora-o-capitalismo-faliu-o-que-vira-a-seguir.shtml

- HOFFMAN, Scott L. The law and business of international project finance. New York: Cambridge University Press, 2008.

- HOLMES, O. W. Jr. The path of the Law. (in 10 Harvard Law Review 457, 1897). Disponível em: http://www.gutenberg.org/files/2373/2373-h/2373-h.htm. Ultimo acesso em 13 de janeiro de 2013.

- HORSEFIELD, James Keith. The International Monetary Fund: 1945-1965: Twenty years of International Monetary Cooperation, Vol. 1-3. Washington: IMF, 1969.

- HUCK, Hermes Marcelo. Contratos com o Estado: aspectos de direito internacional. São Paulo: Gráfica Editora Aquarela S.A., $1^{\text {a }}$ Ed., 1989.

- HUNTER, David. «The World Bank New Inspection Panel: Will It Increase the Bank's Accountability? » (in Center for International Environmental Law CIEL brief $n^{\circ}$ 1. Washington: 1994). Disponível em: http://www.ciel.org/Publications/issue1.html. Último acesso em: 03 de janeiro de 2013.

- HYDE, James N. Economic Development Agreements. (RCADI-1962-I, T. 105, pp. 267-374).

- JACKSON, John H.; DAVEY William J.; SYKES Alan O. Jr. Legal problems of international economic relations: cases, materials and text on national and international regulation of transnational economic relations. St. Paul, MN: West Publishing Co., 1995. 
- JACQUÉ, Jean-Paul. «A propos de la promesse unilatérale » (in Le droit international - unité et diversité (Mélanges offerts à Paul Reuter), Paris : Pedone, 1981)

- JAMES, Harold. «From grandmotherliness to governance: the evolution of IMF conditionality» (in Finance \& development - v. 35, n²4), Washington: FMI, 1998. Disponível em: http://www.imf.org/external/pubs/ft/fandd/1998/12/james.htm. Acesso em 09/10/2012

- JAYME, Erik. Idéntité culturelle et intégration: le droit international privé postmoderne (RCADI 1995- II, T 251, pp. 9-267).

- JAYME, Erik. Le droit international privé du nouveau millénaire : la protéction de la personne humaine face à la globalisation. Académie de Droit International de la Haya (Conférence prononcée le 24 juillet 2000).

- JEANNENEY, Sylviane. G. Monnaie et finances. Paris: PUF, 1998

- JENKS, Clarence Wilfred. El derecho comun de la humanidad. Madrid: Editorial Tecnos, 1968.

- JENKS, Clarence Wilfred. Direito, Liberdade e Bem-estar. Rio de Janeiro; São Paulo; Lisboa: Editora Fundo de Cultura, 1964.

- JENNINGS, Robert Yewdall. «State Contracts in international law» (in 37 Brit. Y. B. Int'l $\quad$ L. $156 \quad$ 1961) Disponível em http://heinonline.org/HOL/LandingPage?collection=journals\&handle=hein.journals /byrint37\&div=6\&id=\&page=. Acesso em 14 de fevereiro de 2012.

- JÈZE, Gaston. La garantie des emprunts publics d'Etat (RCADI 1925, vol. 7, pp. 151-236).

- JUILLARD, Patrick. L'évolution des sources du droit des investisssements (RCADI-1994-VI, T. 250, pp. 9-215).

- KAPUR, Devesh ; LEWIS, John P.; WEBB, Richard C. The World Bank: its first half century (vol. 1 e 2). Washington: Brookings Institution Press, 1997.

- KELEMEN, R. Daniel; SIBBITT, Eric C. «The Globalization of American Law» (in International Organizations, $\mathrm{n}^{\circ}$ 58, 2004, pp. 103-136) Disponível em < http://fas-polisci.rutgers.edu/dkelemen/research/kelemensibbitt_globalizationofamericanlaw.pdf >. Último acesso em 13 de janeiro de 2013. 
- KEYNES, John Maynard. The collected writings of John Maynard Keynes. Volume XXV: Activities 1940-1944. Shaping the Post-War World: The Clearing Union. Cambridge: Cambridge University Press, 1980.

- KEYNES, John Maynard. The collected writings of John Maynard Keynes. Volume XXVI: Activities 1941-1946. Shaping the Post-War World: Bretton Woods and Reparations. Cambridge: Cambridge University Press, 1980.

- KINNEAR, Meg. Introduction to ICSID: International Centre for Settlement of Investment Disputes. Washington, D.C.: Conferência proferida na American University - Washington College of Law, em 5 de abril de 2012.

- KIMBALL, Warren F. Churchill \& Roosevelt, the complete correspondence (vol. II). Princeton, NJ: Princeton University Press, 1984.

- KISSINGER, Henry. Diplomacy. New York: Simon \& Schuster Paperbacks, 1994.

- KRUEGER, Anne O. «Whither the World Bank and the IMF? 》 (in NBER Working Paper, n. 6327, Cambridge, MA, NBER, 1997) Disponível em <http://www.nber.org/papers/w6327>. Último acesso em 13 de janeiro de 2013.

- KUMAR, Krishan. Da sociedade pós-industrial à pós-moderna: Novas teorias sobre o mundo contemporâneo. Rio de Janeiro: Jorge Zahar Ed. 2006.

- KUNZ, Josef L. La crise et les transformations du droit des gens (RCADI 1955, vol. 88, issue II, pp. 1-104)

- LA PORTA, Rafael ; LOZEZ-DE-SILANE, Florencio ; SHLEIFER, Andrei ; VISHNY, Robert W. «Legal determinants of external finance» (in Journal of Finance, volume 52, $\mathrm{n}^{\circ}$ 3, 1997, p. 1131-1150)

- LALIVE, Jean-Flavien. Contrats entre Etats ou entreprises étatiques et personnes privées: développements récents (RCADI 1983, vol. 181, pp. 9-234).

- LAlive, Jean-Flavien. L'immunité de juridiction des Etats et des Organisations Internationales (RCADI 1953, vol. 84, pp. 205-396)

- LAUTERPACHT, Elihu. «Gentleman's agreements». (in Internationales Recht und Wirtschaftsordnung: Festchrift für F. A. Mann, Munich: Werner Flume, 1977)

- LAUTERPACHT, Hersch. The function of law in the international community. New Jersey: The Lawbook exchange, Ltd., 2005. 
- LAVALLE, Roberto. La Banque Mondiale et ses filiales : aspects juridiques et fonctionnement. Paris: Librairie Générale de Droit et de Jurisprudence, Collections Bibliothèque de droit international 65, 1972.

- LE FUR, Louis-Erasme. Le développement historique du droit international. (RCADI-1932, T. 41, p. 501-601)

- LEBEN, Charles. La théorie du Contrat d'Etat et l'évolution du droit international des investissements (RCADI 2003, vol. 302, pp. 197-386).

- LELART, Michel. Le système monétaire international. Paris : La Découverte, Coll. Répères, 2003.

- L'HUILlier, Jacques A. Théorie et Pratique de la Coopération Économique Internationale. Paris: Éditions M. Th. Génin, 1957.

- LOTMAn, Yuri. La Semiosfera: vol. I: Semiótica de la cultura y del texto. Madrid: Ediciones Cátedra, série Frónesis, 1996.

- LOWENFELD. Andreas F. International economic law. New York: Oxford University Press, 2008

- MALANCZUK, Peter. Akehurst's modern introduction to International Law, London: Routledge, 1997.

- MANN, Frederick Alexander. «Law Governing State Contracts» in 21 Brit. Y. B. Int'l L. 11 (1944). Disponível em: http://heinonline.org/HOL/LandingPage?collection=journals\&handle=hein.journals /byrint $21 \&$ div=6\&id=\&page=. Acesso em 25 de outubro de 2012.

- MARiguetto, Andrea. O Acesso ao Contrato: sentido e extensão da função social do contrato. São Paulo: Quartier Latin, 2012.

- MARSHALL, Katherine. The World Bank: from reconstruction to development to equity. New York: Routledge (Taylor \& Francis Group), 2009.

- MARTY, Frédéric ; TROSA, Sylvie ; VOISIN, Arnaud. Les partenariats publicprivé. Paris : La Découverte, Collection Repères, 2006.

- MASON, Edward S.; ASHER, Robert E. The World Bank since Bretton Woods. Washington: The Brookings Institute, 1973.

- MATTOUT, Jean-Pierre. Droit bancaire international. Paris : Revue Banque Édition, 2004. 
- MATTOUT, Jean Pierre. «O financiamento de projeto ou o poder do contrato » (in Revista de direito bancário e do mercado de capitais - ano 2, $\mathbf{n}^{\circ}$ 4), São Paulo: Editora Revista dos Tribunais, janeiro-abril/1999, pp. 71-79)

- MAYER, Pierre «La neutralisation du pouvoir normatif de l'Etat en matière de contrats d'Etat » (in Journal du Droit International, Paris: jan/fev/mar 1986, pp. $5-78)$

- MELlO, Celso D. de Albuquerque. Curso de direito internacional (Vols. I e II). Rio de Janeiro: Renovar, 2004.

- MERRIEN, François-Xavier. L'État-providence. Paris: PUF, 2007.

- MIRANDA, Luiz Ricardo de. Les lettres d'intention au Fonds Monétaire International. Tese apresentada para obtenção do título doutor em direito em direito e financiamento do desenvolvimento. Institut du Droit de la Paix et du Développement - Université de Nice Sophia Antipolis, 2007.

- MIRANDA, Luiz Ricardo de. Le processus de libéralisation financières : les leçons du Brésil, du Chili et de l'Argentine. Mémoire apresentado para obtenção do DEA - Diplôme d'Études Approfondies em direito em direito e financiamento do desenvolvimento. Institut du Droit de la Paix et du Développement - Université de Nice Sophia Antipolis, 2002.

- MOSES, Margaret L. The Principles and Practice of International Commercial Arbitration. New York: Cambridge University Press, 2010.

- NASSER, Salem Hikmat. Fontes e normas do Direito Internacional: um estudo sobre a soft law. São Paulo: Atlas, $2^{a}$. Ed., 2006.

- NEVITT, Peter. K.; FABOZZI, Frank. Project financing. London: Euromoneybooks, 2000.

- NIXON, Richard. "Private Investment and the economic change» (in The Department of State Bulletin, v. 37, $\mathrm{n}^{\circ}$ 958, pp. 703-707, Out/Dez.1957). Disponível em: http://archive.org/details/departmentofstat3757unit. Último acesso em 28 de novembro de 2012.

- NUSDEO, Fábio. Curso de economia: introdução ao direito econômico. São Paulo: Ed. Revista dos Tribunais, 2008.

- NUSDEO, Fábio. Fundamentos para uma codificação do direito econômico. São Paulo: Ed. Revista dos Tribunais, 1995. 
- NUSSBAUM, Arthur. A concise history of the law of nations. New York: The Macmillan Company, 1947.

- NUSSBAUM, Arthur. Uma história do dólar. Rio de Janeiro: Zahar Editores, 1967.

- OFFE, Claus. Problemas estruturais do Estado capitalista. Rio de Janeiro: Tempo Brasileiro, 1984.

- ÖRÜCÜ, Esin. «Law as transposition» (in The International and Comparative Law Quarterly, vol. 51, $\mathrm{n}^{\circ}$ 2, Abr. 2002, pp. 205-223) Disponível em < http://www.jstor.org/stable/3663227 > Último Acesso em 13 de janeiro de 2013

- OSIEKE, Ebere. «The Legal Validity of Ultra Vires Decisions of International Organizations» (in The American Journal of International Law, Vol. 77, No. 2, Abr., 1983, pp. 239-256) Disponível em: http://www.jstor.org/stable/2200852. Último acesso em: 10 de abril de 2012.

- OSIEKE, Ebere. «Unconstitutional Acts in International Organisations: The Law and Practice of the ICAO» (in The International and Comparative Law Quarterly, Vol. 28, No. 1, Jan., 1979, pp. 1-26) Disponível em: http://www.jstor.org/stable/758550. Último acesso em: 10 de abril de 2012.

- PASTOR RIDRUEJO, José Antonio. Le droit international à la veille du vingt et unième siècle : normes, faits et valeurs (RCADI 1998, T. 274, pp. 9-308).

- PAULSSON, Jan. "Indirect expropriation: is the right to regulate at risk?". (In Making the most of international agreements: a common agenda, Symposium Co-organised by ICSID, OECD and UNCTAD, Paris: OECD Headquarters, 12 de dezembro de 2005).

- PAVANI, Sérgio Augusto Zampol ; ANDRADE, Rogério Emílio (Org.). Parcerias público-privadas. São Paulo: MP Editora, 2006.

- PELLET, Alain. Le droit international du développement. Paris : P.U.F., 1987.

- PEREIRA, Antonio Celso Alves. «O recurso à força pelos estados e a legítima defesa no direito internacional contemporâneo» (in Novas perspectivas do direito internacional contemporâneo - Estudos em homenagem ao Professor Celso D. de Albuquerque Mello, Carlos Alberto Menezes Direito, Antonio Augusto Cançado Trindade, Antonio Celso Alves Pereira (org). Rio de Janeiro: Renovar, 2008)

- PEREIRA, João Márcio Mendes. O Banco Mundial com ator político, intelectual e financeiro (1944-2008). Rio de Janeiro: Editora Civilização Brasileira, 2010. 
- PETITEVILlE, Frank. «Les figures mythiques de l'Etat dans l'économie du développement» (in Revue Problèmes économiques, - $\mathrm{n}^{\circ} 2587$, octobre 1998 - p. 14-20).

- PHILLIPS, David A. Reforming the World Bank: Twenty years of trial - and error. New York: Cambridge University Press, 2009.

- PIQUEMAL, Alain. «La notion de 'conditionnalité' et les organisations internationales économiques et financiéres» (in Mélanges en l'honneur du Doyen Pual Isoart. Paris : Pedone, 1996, pp. 306-318).

- POGGI, Gianfranco. A evolução do Estado moderno - uma introdução sociológica. Rio de Janeiro: Zahar Editores, 1981.

- PORTER, Gilbert. «Risk is not so political after all» (in Global Infrastructure Development: World Markets in 1999, Washington DC: $7^{\circ}$ Annual World Economic Development Congress, 1998, p. 63-67)

- POSNER, R. A. «Theories of economic regulation». (in The Bell Journal of Economics and Management Science, vol. 5, n. 2, p. 335, 1974). Disponível em: < http://www.jstor.org/stable/3003113 >. Acesso em 21 de fevereiro de 2012.

- RACHED, Gabriel. «A evolução das políticas de desenvolvimento do Banco Mundial no contexto das transformações internacionais» Toulouse: VI Congresso CEISAL, 2010. Acesso em: 20.08.2012, http://halshs.archivesouvertes.fr/docs/00/49/61/94/PDF/GabrielRached.pdf

- RANGEL, Vicente Marotta. Direito e relações internacionais. São Paulo: Revista dos Tribunais, 2005.

- RAUSTIALA, Kal. «Form and substance in international agreements» (in American Journal of International Law - volume 99, $\mathbf{n}^{\circ}$ 3, Washington: American Society of International Law, julho/2005 - p. 581-614)

- REALE, M. Filosofia do direito. São Paulo: Saraiva, 2008.

- REUTER, Paul. Droit international public. Paris : Presses Universitaires de France, 1993.

- REUTER, Paul. Institutions internationales. Paris: Presses Universitaires de France, Coll. Thémis, 1962.

- REUTER, Paul. Introduction au droit des Traités. Paris : Presses Universitaires de France, 1995. 
- REUTER, Paul. Mélanges. Le Droit international: unité et diversité public (Mélanges offerts à Paul Reuter). Paris: Pedone, 1981.

- REUTER, Paul. Mélanges. Principes de droit international public. (RCADI1961-II, vol. 103, pp. 425-656)

- REZEK, José Francisco. Direito internacional público. São Paulo: Saraiva, 2007.

- RIGAUX, François. Nouveaux itinéraires em droit: hommage à François Rigaux (Mélanges Rigaux). Bruxelas: Bruylant, 1993.

- RIGAUX, François. Droit public et droit privé dans les relations internationales. Paris: Pedone, 1977, p. 373.

- ROCHE, Jean-Jacques. Le système international contemporain. Paris : Montchrestien, 1998.

- RODRIK, Dani. «Why is there multilateral lending?» (in NBER Working Paper (n. 5160), Cambridge, MA: NBER, 1995)

- SALOMÃO FILHO, Calixto. «Globalização e teoria jurídica do conhecimento econômico», (in Direito Global, São Paulo: Max Limonad, 1999)

- SAlomão FILHO, Calixto. Regulação da atividade econômica: princípios e fundamentos jurídicos. São Paulo: Malheiros, 2008.

- SALOMÃO FILHO, Calixto. Regulação e concorrência: estudos e pareceres. São Paulo: Malheiros, 2002.

- SAlOMÃO NETO, Eduardo. Direito bancário. São Paulo: Atlas, 2005.

- SALOMÃO NETO, Eduardo. «O financiamento de projetos com recursos internacionais (Project finance)» (in Revista de direito bancário e do mercado de capitais - ano 7), São Paulo: Editora Revista dos Tribunais, janeiromarço/2004, pp. 53-92)

- SAlOMÃO NETO, Eduardo. O trust e o direito brasileiro. São Paulo: LTR, 1996.

- SANTOS, Alvaro. «Carving Out Policy Autonomy for Developing Countries in the World Trade Organization: The Experience of Brazil and Mexico » (in Virginia Journal of International Law, Vol. 52, $\mathbf{n}^{\circ}$ 3, Charlottesville, VA: 2012). Disponível em : http://papers.ssrn.com/sol3/papers.cfm?abstract_id=2030966 Acesso em 19 de setembro de 2012.

- SANTOS, Alvaro. "The World Bank's uses of the 'rule of law' promise in economic development » (in The new law and economic development: a critical 
appraisal, New York: Cambridge University Press, 2006). Disponível em http://www.utexas.edu/law/faculty/pubs/as8448_pub.pdf. Acesso em 19 de setembro de 2012.

- SAUNIER, Philippe. «Le système financier et monétaire international» (in Droit international de l'économie, Paris : Ellipses Editions, 2007, pp. 67-184)

- SCANNAVINO, Aimé. Les marchés financiers internationaux. Paris : Dunod, 1999.

- SCHERMERS, Henry G. «The legal bases of international organization action» (in Manuel sur les organisations internationales - a handbook on international organizations, Dordrecht ; Boston ; Lancaster : Martinus Nijhoff Publisheurs, 1998)

- SEKFALI, Zine. Droit des financemets structurés. Paris: Revue Banque Édition, 2004

- SHIHATA, Ibrahim F. I. «Democracy and development» (in The International and Comparative Law Quartely - Vol. 46, $n^{\circ}$ 03, pp. 635-643, julho 1997). Disponível em http://www.jstor.org/stable/761277. Acesso em: 28.02.2012.

- SHIRATA, Ibrahim F. I. The Legal Treatment of Foreign Investment: The World Bank Guidelines. Dordrecht; London; Boston: Martinus Nijhoff Publisheurs, 1993.

- SHIRATA, Ibrahim F. I. The Multilateral Investment Guarantee Agency (MIGA) and the legal treatment of foreign investments (RCADI-1987-III, vol. 203, pp. 95-320).

- SHIRATA, Ibrahim F. I. The World Bank in a changing world: Selected Essays. Dordrecht ; London ; Boston: Martinus Nijhoff Publisheurs, 1991.

- SHIRATA, Ibrahim F. I. The World Bank in a changing world (Vol. III). Hague ; London ; Boston: Martinus Nijhoff Publisheurs, 2000.

- SHIRATA, Ibrahim F. I. The World Bank Legal Papers. Dordrecht ; London ; Boston: Martinus Nijhoff Publisheurs, 2000.

- ShIRATA, Ibrahim F. I. The World Bank Inspection Panel: in Practice. New York: Oxford University Press, 2000.

- SOARES, Guido Fernando Silva. Curso de direito internacional público. São Paulo: editora Atlas, 2004.

- SOLOMON, Robert. O sistema monetário internacional: 1945-1976. Rio de Janeiro: Zahar, 1979. 
- SORNARAJAH, Muthucumaraswamy. The international law on foreign investment. New York: Cambridge University Press, $3^{\text {a }}$ edição, 2010.

- SQUIRE, Lyn. «Why the World Bank should be involved in development research» (in The World Bank: structure and policies. Cambridge: Cambridge University Press, 2000, pp. 108-131)

- STIGLER, George. J. «The Theory of Economic Regulation» (In The Bell Journal of Economics and Management Science, vol. 2, n. 1, p. 3-21, 1971). Disponível em < http://www.jstor.org/stable/3003160> Acesso em 8 de agosto de 2008.

- STIGLITZ, J. E. «Introduction» (in The World Bank: structure and policies, GILBERT, Christopher L.; VINES, David (Org.), Cambridge: Cambridge University Press, 2000).

- SUNDFELD, Carlos Ari. «A administração pública na era do direito global» (in Direito Global, São Paulo: Max Limonad, 1999)

- SUNDFELD, Carlos Ari (Org.). Parcerias Público-Privadas. São Paulo: Malheiros, 2005.

- SUNDFELD, Carlos Ari; VIEIRA, Oscar Vilhena (Org.) Direito Global, São Paulo: Max Limonad, 1999.

- SUREDA, Andrès Rigo. The law applicable to the activities of International Development Banks (RCADI-2004, volume 308 , pp. 9-252).

- SØRENSEN, Max. Principes de droit international public: cours général (RCADI 1960, vol. 101, issue III, pp. 1-254).

- TEULON, Frédéric. Les pays en développement. Paris: Hachette, Coll. Les Fondamentaux, 1999.

- TIMMER, Peter. «Quel modèle de développement» (in Problèmes économiques, $\mathrm{n}^{\circ} 2480$, jul. 1996, pp. 1-4)

- TIMSIT, Gérard. «Critique de la gestion pure: du changement dans le secteur public des pays d'Europe occidentale». (In Revue Internationale de Politique Comparée, Vol. 11, $\left.\mathrm{n}^{\circ} \quad 2, \quad 2004\right) \quad$ Disponínel em $<$ http://www.uclouvain.be/cps/ucl/doc/pols/documents/Critique_de_la_gestion_pur e.pdf> Último acesso em 13 e janeiro de 2013.

- TIMSIT, Gérard. «La régulation. La notion et le phénomène » (in Revue française d'administration publique, $\mathrm{N}^{\circ} 109,2004-1, \quad$ p. 5-11) Disponível em 
<http://www.cairn.info/article.php?ID_REVUE=RFAP\&ID_NUMPUBLIE=RFAP _109\&ID_ARTICLE=RFAP_109_0005> Acesso em 19 de março de 2009.

- TOLEDO, Anne-Marie ; LIGNIÈRES, Paul. Le financement de projet. Paris: Loly, 2002.

- TRINDADE, Antonio Augusto Cançado. Princípios do Direito Internacional Contemporâneo. Brasília: Editora Universidade de Brasília, 1981.

- TRUBEK, David M.; SANTOS, Alvaro (ed.). The new law and economic development: a critical appraisal, New York: Cambridge University Press, 2006.

- TRUYOL Y SERRA, Antonio. Histoire du droit international. Paris: Economica, 1995

- TRUYOL Y SERRA, Atonio. L'expansion de la société internationale aux XIX et $\mathbf{X X}^{\mathrm{e}}$ siècles (RCADI-1965, volume 116, issue III , pp. 89-179).

- TRUYOL Y SERRA, Atonio. Genèse et structure de la société internationale (RCADI-1959-I, vol. 96, pp. 553-642).

- TUNKIN, Grigory I. Theory of international law. Massachusetts: Harvard University Press, 1974.

- UDALL, Lori. The World Bank Inspection Panel: A Three Year Review. Washington: Bank Information Center, 1997.

- VERDROSS, Alfred. «On the Concept of International Law» (in The American Journal of International Law, Vol. 43, No. 3 - Julho de 1949, pp. 435-440). Disponível em: http://www.jstor.org/stable/2193637. Acesso em: 12/08/2009.

- VERDROSS, Alfred. «Quase-International Agreements and International Economic Transactions » (in Yearbook of World Affairs, 1964, pp. 230-247)

- VERHOEVEN, Joe. «Les activités normatives et quasi normatives » (in Manuel sur les organisations internationales - a handbook on international organizations, Dordrecht ; Boston ; Lancaster : Martinus Nijhoff Publisheurs, 1998)

- VIRALLY, Michel. «A propos de 'lex ferenda'» (in Le droit international - unité et diversité : Mélanges offerts à Paul Reuter. Paris : Pedone, 1981).

- VIRALLY, Michel. «La valeur juridique des recommandations des organisations internationales » (in Annuaire Français de Droit International, Paris : Pedone, 1956). 
- VIRALLY, Michel. «La distinction entre textes internationaux ayant une portée juridique entre leurs auteurs et textes qui en sont dépourvus» (in Annuaire IDI, Paris: Pedone, 1983, p. 166-257)

- VIRALLY, Michel. L'organisation mondiale. Paris: Colin, 1972.

- VINTER, Graham D. Project finance. Londres: Sweet \& Maxwell, 1995

- WAlleRSTEIN, Immanuel. «C'était quoi, le Tiers monde? (in Problèmes économiques, $\mathrm{n}^{\circ} 2684$, out. 2000, pp.1-5)

- WEAVER, James H. The International Development Association: A new approach to foreign aid. New York: Praeger, 1965.

- WEIL, Prosper. Le droit international en quête de son identité (RCADI-1992VI, T. 237, pp. 9-370).

- WEIL, Prosper. Problèmes relatifs aux contrats passés entre un Etat et un particulier (RCADI-1969, T. 128, pp. 95-240).

- WEIL, Prosper. «Vers une normativité relative en droit international ?» (in Revue Générale de Droit International Public - Tome LXXXVI. Paris: Pedone, 1982 - pp. 5-47)

- WENGLER, Wilhelm. «Les conventions 'non juridiques' (nichtrechtliche verträge) comme nouvelle voie à côté des conventions en droit (rechtsverträge)» (in Nouveaux itinéraires en droit : Hommage à François Rigaux : Mélanges Rigaux, Bruxelas : Bruylant, 1993, pp. 637-656)

- WILliAMSON, John (org.). IMF Conditionality. Washington: Institute for International Economics, 1983.

- WILLIAMSON, John. «The lending policies of the International Monetary Fund» (in IMF Conditionality, Washington: Institute for International Economics, 1983).

- WISE, Eward. M. «The transplant of legal patterns » (in The American Journal of Comparative

Law

Vol. 38, Supplement, 1990) Disponível em < http://www.jstor.org/stable/840531 > Último acesso em 13 de janeiro de 2013.

- WOLFENSOHN, James D. «The Other crisis». Discurso proferido na reunião do Conselho de Governadores do BIRD em 6 de outubro de 1998. Disponível em: http://siteresources.worldbank.org/NEWS/Resources/jdwsp100698-en.pdf. Acesso em 29 de agosto de 2012 
- WOOD, Philip R. International loans, bonds and securities regulation. Londres: Sweet \& Maxwell, 1995.

- WOOD, Philip R. Project finance, subordinated debt and state loans. Londres: Sweet \& Maxwell, 1995.

- WOODS, Ngaire. «The Challenges of multilateralism and governance» (in The World Bank : structure and policies). Cambridge: Cambridge University Press, 2000

- YESCOMBE, Edward R. Principles of Project Finance. Oxford: Academic Press (Elsevier), 2002.

- ZEIN, Youmna. Les pools bancaires: aspects juridiques. Paris: Economica, 1998.

- ZEMANEK, Karl. The legal foundations of the international system (RCADI1997, T. 266).

- ZWEIGERT, Konrad ; KÖTZ, Hein. Introduction to comparative law. New York: Oxford University Press, 1992.

Institucionais

- BANCO MUNDIAL. Good Practice Note for Development Policy Lending: designing development policy operations. Washington, DC: World Bank, 2011.

- BANCO MUNDIAL. World development report 2002 - building institutions for market. New York: Oxford University Press, 2002.

- BANCO MUNDIAL. World development report 2005 - a better investment climate for everyone. New York: World Bank and Oxford University Press, 2005.

- BANCO MUNDIAL. World Investment and Political Risk 2009. Washington: World Bank, 2010.

- BANCO MUNDIAL. Accelerated Development in Sub-Saharan Africa: an agenda for action. Washington: World Bank, 1981. Disponível em: http://wwwwds.worldbank.org/external/default/WDSContentServer/WDSP/IB/2000/04/13/000 178830_98101911444774/Rendered/PDF/multi_page.pdf. Acesso em 12 de setembro de 2012 .

- BANCO MUNDIAL. Toward sustained development in Sub-Saharan Africa. Washington, DC: World Bank, 1984. Disponível em: http://wwwwds.worldbank.org/external/default/WDSContentServer/WDSP/IB/2000/02/17/000 


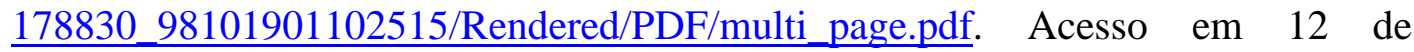
setembro de 2012.

- BANCO MUNDIAL. Private Sector Development: Strengthening the Bank Group Effort. Washington, DC: World Bank, 1991.

- BANCO MUNDIAL. Sub-Saharan Africa: from crisis to sustainable growth. Washington, DC: World Bank, 1989. Disponível em: http://wwwwds.worldbank.org/external/default/WDSContentServer/WDSP/IB/1999/12/02/000 178830_98101901364149/Rendered/PDF/multi0page.pdf. Acesso em 12 de setembro de 2012.

- BANCO MUNDIAL (Independent Evaluation Group). The World Bank Group Guarantee Instruments 1990-2007: An Independent Evaluation. Washington: World Bank, 2009.

- BANQUE CENTRALE EUROPEENNE. «Les évolutions récentes de la coopération internationale » (in Bulletin mensuel de la BCE, Banco Central Europeu, fevereiro 2002)

- FUNDO MONETARIO INTERNACIONAL; BANCO MUNDIAL. Strengthening IMF-World Bank collaboration on country programs and conditionality - progress report. Washington, FMI, 2002.

- FUNDO MONETARIO INTERNACIONAL (Staff paper). Fund Conditionality: a provisional update. Washington, DC: FMI, 2004

- FUNDO MONETARIO INTERNACIONAL (Departamento de Tesouraria). Organisation et opérations financières du FMI. Washington, D.C.: FMI (Série des brochures - $\mathrm{n}^{\circ}$ 45-F), 2001.

- INTERNATIONAL FINANCE CORPORATION (IFC). Project finance in development countries. Lessons of experience $\mathbf{n}^{\circ}$ 7, Washington : 1999.

- CORTE INTERNACIONAL DE JUSTIÇA. Caso Reparação dos danos sofridos em serviço da ONU (Injuries case). Consulta de 11 de abril de 1949. Disponível em : http://www.icj-cij.org/docket/files/4/1834.pdf. Acesso em 24 de junho de 2011.

- CORTE INTERNACIONAL DE JUSTIÇA. Caso Barcelona Traction, Light and Power Company, Limited (2 ${ }^{\mathrm{a}}$ Demanda). Decisão de 05 de fevereiro de 1970. Disponível em: http://www.icj-cij.org/docket/files/50/5386.pdf. Acesso em: 24 de junho de 2011. 
- CORTE PERMANENTE DE JUSTIÇA INTERNAIONAL. Caso Vapeur “Wimbledon”. Decisão de 17 de agosto de 1923. Disponível em: http://www.icjcij.org/pcij/serie_A/A_01/03_Wimbledon_Arret_08_1923.pdf. Acesso em: de junho de 2011.

- CORTE PERMANENTE DE JUSTIÇA INTERNAIONAL. Caso Lotus. Decisão de 7 de setembro de 1927, série A, $\mathrm{n}^{\circ}$ 10. Disponível em: http://www.icjcij.org/pcij/serie_A/A_10/30_Lotus_Arret.pdf. Acesso em: 13 de junho de 2011.

- MUltilateral INVESTMENT GUARANTEE AGENCY (MIGA), Commentary on the Convention Establishing the Multilateral Investment Guarantee Agency. Washington, D.C.: MIGA. Disponível em http://www.miga.org/documents/commentary_convention_november_2010.pdf. Acesso em: 3 de janeiro de 2013. 